\title{
COMBINED MASS SUCTION AND BUOYANCY EFFECTS ON HEAT TRANSFER AND GAS FLOW IN A FUEL CELL DUCT
}

\author{
Jinliang Yuan, Masoud Rokni, and Bengt Sundén \\ Division of Heat Transfer, Lund Institute of Technology, \\ Lund, Sweden
}

\begin{abstract}
A numerical study was carried out to examine the development of duct flows being affected by combined buoyancy force-driven secondary flow and mass transfer. The developing flow and heat transfer have been simulated numerically for a horizontal fuel cell duct with rectangular and trapezoidal cross section. Constant heat flux and mass transfer rate are prescribed on the bottom wall, while thermal insulation is implemented on the other three impermeable walls. The buoyancy-generated secondary flow and mass transfer can disrupt the hydrodynamic and thermal boundary layers, and thus affect the friction factor and Nusselt number. Calculations have been performed to determine the effects of various Grashof number, mass transfer rate, and Reynolds number. Comparisons of these numerical results with available data are presented.
\end{abstract}

\section{INTRODUCTION}

Analyses and simulations of gas utilization, produced power, energy efficiency, electrical current, temperature distribution, and mechanical stress in unit cells of a fuel cell stack have been presented in the literature for solid oxide fuel cells (SOFCs). The energy balance equation is usually employed in the thermal analysis and calculations of temperature distributions. However, the assumptions concerning the convective heat transfer coefficients for the flows of the fuel and the oxidant, see [1-6], are usually based on constant Nusselt numbers which are available for fully developed laminar flow in the published literature. Through a literature survey covering the relevant problems of heat transfer and gas flow modeling, see [7], it was found that there is no study simulating and analyzing heat transfer and pressure drop in fuel cell ducts in terms of friction factor $f$ and Nusselt number $\mathrm{Nu}$, respectively. The unique mass transfer and thermal boundary conditions of fuel cells have not been considered properly. The flow ducts for the fuel and the oxidant are usually identical in the model and uniform throughout the entire fuel cell stack. This is not very appropriate if an even temperature distribution is attempted, and if

Received 15 June 2001; accepted 7 June 2002.

The research presented is financially supported by the National Fuel Cell Programme of the Swedish Energy Agency.

Address correspondence to B. Sundén, Division of Heat Transfer, Lund Institute of Technology, Box 118, S-22100 Lund, Sweden. E-mail: bengt.sunden@vok.lth.se 


\begin{tabular}{|c|c|c|c|}
\hline \multicolumn{4}{|c|}{ NOMENCLATURE } \\
\hline$a$ & width of lower wall & $x, y, z$ & Cartesian coordinates \\
\hline$A$ & cross-section area & $x^{*}$ & hydrodynamic dimensionless axial \\
\hline$b$ & width of upper wall & & distance $\left(=x / D_{h} \mathrm{Re}\right)$ \\
\hline$c_{p}$ & specific heat at constant pressure & $x^{* *}$ & thermal dimensionless axial distance \\
\hline$D_{h}$ & hydraulic diameter & & $\left(=x^{*} / \operatorname{Pr}\right)$ \\
\hline$f$ & Fanning friction factor & $\beta$ & coefficient of thermal expansion \\
\hline$g$ & acceleration due to gravity & $\mu$ & dynamic viscosity \\
\hline $\mathrm{Gr}^{*}$ & modified Grashof number & $v$ & kinematic viscosity \\
\hline & $\left(=g \beta q_{b} D_{h}^{4} / k v^{2}\right)$ & $\rho$ & density \\
\hline$h$ & height of the duct & & \\
\hline$h_{b}$ & heat transfer coefficient & \multirow{2}{*}{\multicolumn{2}{|c|}{ Subscripts }} \\
\hline$k$ & thermal conductivity & & \\
\hline$\dot{m}$ & mass flow rate & $b$ & bottom wall \\
\hline $\mathrm{Nu}$ & Nusselt number & bulk & bulk fluid condition \\
\hline$P$ & pressure & in & inlet \\
\hline$P^{*}$ & wetted perimeter & $m$ & mass transfer \\
\hline$q$ & heat flux & out & outlet \\
\hline $\mathrm{Re}$ & Reynolds number $\left(=U D_{h} / v\right)$ & ref & reference \\
\hline $\operatorname{Re}_{m}$ & wall Reynolds number $\left(=V_{m} D_{h} / v\right)$ & $w$ & wall \\
\hline$S$ & source term & & \\
\hline$T$ & temperature & & \\
\hline$U, V, W$ & \multicolumn{3}{|c|}{ Superscripts } \\
\hline & velocity components in $x, y$, and $z$ & - & cross-section averaged value \\
\hline & directions, respectively & $*$ & definition for $x^{*}$ \\
\hline$V_{m}$ & mass transfer velocity at bottom wall & $* *$ & definition for $x^{* *}$ \\
\hline
\end{tabular}

the pressure drop for each fluid should be kept within certain limits in relation to other components in the system. Thus there is a need to deepen and further develop such analyses to achieve heat transfer coefficients and pressure drop (friction factor) which are valid for the fuel-cell boundary conditions.

Several fundamental studies of flow characteristics in ducts with different cross sections exist in the literature. Most of the recent studies concern turbulent flow in ducts; e.g., Rokni and Sundén [8] and Rokni [9] simulated turbulent gas flow and heat transfer in ducts with different cross sections using different turbulence models. The thermal boundary condition of either constant temperature or constant heat flux on all walls was implemented in these studies.

Because both the heat transfer and the pressure drop (friction factor) are significantly affected, the fluid flow and heat transfer in ducts with mass transfer in porous walls have received a great deal of attention in the past decades [10-12]. By employing the vorticity-velocity method with a marching technique, Hwang et al. [10] simulated forced-convective heat transfer and gas flow in a square duct with one porous wall with injection and suction in the range $-20.0<\operatorname{Re}_{m}<20.0$, where $\operatorname{Re}_{m}$ is a Reynolds number based on mass transfer velocity through the wall. As the fluid passes along a heated bottom wall of a horizontal duct, it becomes warmer and less dense than the bulk fluid in the core, and a small reduction in pressure is created, which accelerates the flow, and protrudes upward like a plume. Studies of mixed convection in horizontal ducts without mass transfer were conducted and presented in [13-19]. The mass transfer and buoyancy force-induced secondary flows, which 
have significant effects on the internal duct flow and heat transfer, have been investigated extensively in the last decades. Moreover, the combined effects of mass transfer from all walls and buoyancy-driven secondary flows with either uniform heat flux or temperature at all walls have been studied by Lee and Yan [20].

Air $\left(\mathrm{O}_{2}+\mathrm{N}_{2}\right)$ (or oxidant, hereafter) is introduced in the cathode duct of fuel cells. In the electrochemical reaction process, part of the oxygen is consumed and is transferred to oxygen ions in the cathode duct, subject to fluid suction along the porous interface to the electrolyte. Yuan et al. [7] simulated the mass transfer effects on the fully developed laminar flow in rectangular and trapezoidal ducts of fuel cells, with the new combined thermal boundary conditions and mass transfer rates within $-2.5<\operatorname{Re}_{m}<2.5$. The development of buoyancy force-driven secondary flow and effects of various parameters (e.g., Grashof number, Reynolds number), and placement of the heated wall on developing laminar flow in a rectangular fuel cell duct are presented in [21] and [22], respectively. However, the effects of combined mass transfer and buoyancy-driven secondary flow (or combined flow, hereafter) have not been investigated yet.

Both gas flow and heat transfer in fuel cell ducts for developing laminar conditions are studied, numerically thereby considering effects of combined mass transfer and buoyancy force-driven secondary flow. Only results from combined mass suction occurring in oxidant ducts and buoyancy effects are reported in this article. The purpose of the present study is to reveal the basic phenomena of this flow type. These are essential for determination of optimized mass flow rate and obtaining the desired cell temperature at fuel cell conditions. The contribution of this article is that the characteristics of fuel cells (heat generation and mass suction by electrochemical reaction, thermal-physical properties at high temperature) have been taken into account. In addition, the effects of mass suction rate and Grashof number on generation of buoyancy-driven secondary motions, fluid dynamics, and heat transfer are also assessed. It should be noted here that the Gr* in SOFCs is of the order of $10^{4}-10^{5}$, and it is important to reveal whether the buoyancy force has significant influence. The complexity of the combined buoyancy-driven secondary flows and mass suction depends strongly on the Grashof number and wall Reynolds number, as will be found in this study.

\section{ANALYSIS}

\section{Problem Statement}

Navier-Stokes equations, the mass conservation equation, and the energy equation are solved for ducts of a unit fuel cell, see Figure $1 a$. This study is focused on the developing laminar flow and heat transfer with combined mass suction and buoyancy effects. The duct under consideration is shown schematically in Figure $1 b$. The $U, V$, and $W$ are the velocity components in the $x, y, z$ directions, respectively. The aspect ratio of the duct is defined as the ratio between the shortest width of lower or upper wall to duct height (i.e., $a / h$ or $b / h$ ). By changing this ratio and the base angle $\alpha$, different cross-sectional geometries, i.e., square, rectangular, trapezoidal ducts, can be simulated.

A steady laminar flow of an incompressible fluid is considered and all thermalphysical properties are assumed constant, except the linear density variation with 


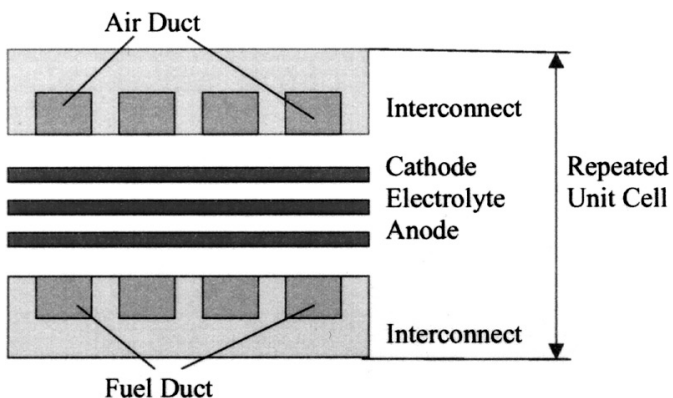

a)

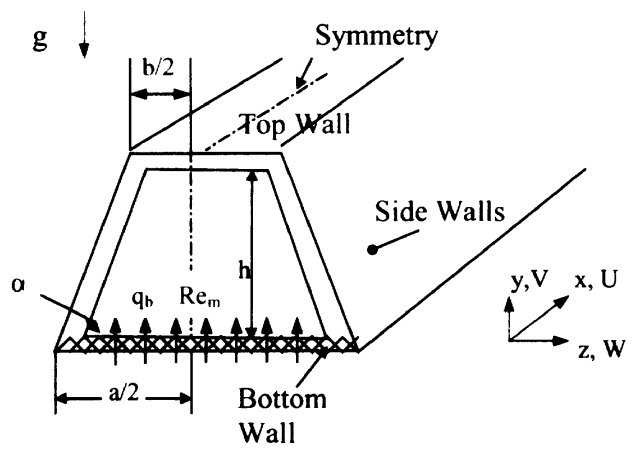

b)

Figure 1. (a) Structure of a unit cell. (b) Schematic drawing of a fuel cell duct.

temperature in the body force term, which appears as buoyancy effects are considered. For simplicity, the following additional assumptions are applied.

1. The axial velocity and temperature distributions of the fluid at the inlet are assumed uniform.

2. A uniform chemical reaction rate is assumed to appear in the electrolyte. The released heat is simulated as a constant wall heat flux $q_{w}$ at one duct wall (bottom wall in this study).

3. When the buoyancy effect is considered, the density variation is small and is approximated as $\left(\rho-\rho^{\prime}\right) / \rho=\beta\left(T-T^{\prime}\right)$, in which $\beta$ is the thermal expansion coefficient.

4. The mass suction is assumed to be small compared to the streamwise flow when the mass transfer effect is considered. The dimensionless suction velocity on the bottom porous wall can be written as [10]

$$
\operatorname{Re}_{m}=\frac{V_{m} D_{h}}{v}
$$


where $\operatorname{Re}_{m}$ is the wall Reynolds number, $V_{m}$ is the mass transfer velocity, $D_{h}$ is the hydraulic diameter, and $v$ is the kinematic viscosity. In this study, $\operatorname{Re}_{m}$ is negative because suction is considered. Moreover, in SOFCs, $\mathrm{Re}_{m}$ is very small and its mean value is of the order of 1.0 for $\mathrm{O}_{2}$ consumption in the air ducts. Based on this fact, the range of $\operatorname{Re}_{m}=0--2.5$ is chosen, which is very small compared to the main flow Reynolds number $\mathrm{Re}_{\mathrm{in}}$.

5. Only one-half of the duct is considered by imposing symmetry conditions on the mid-plane, which reduces the calculation domain by one-half.

\section{GOVERNING EQUATIONS}

For an incompressible Newtonian fluid, the governing equations of fluid flow can be written as the following continuity, momentum, and energy equations:

$$
\begin{gathered}
\frac{\partial U}{\partial x}+\frac{\partial V}{\partial y}+\frac{\partial W}{\partial z}=S_{m} \\
U \frac{\partial U}{\partial x}+V \frac{\partial U}{\partial y}+W \frac{\partial U}{\partial z}=-\frac{1}{\rho} \frac{\partial P}{\partial x}+v\left(\frac{\partial^{2} U}{\partial x^{2}}+\frac{\partial^{2} U}{\partial y^{2}}+\frac{\partial^{2} U}{\partial z^{2}}\right) \\
U \frac{\partial V}{\partial x}+V \frac{\partial V}{\partial y}+W \frac{\partial V}{\partial z}=-\frac{1}{\rho} \frac{\partial P}{\partial y}+v\left(\frac{\partial^{2} V}{\partial x^{2}}+\frac{\partial^{2} V}{\partial y^{2}}+\frac{\partial^{2} V}{\partial z^{2}}\right)+g \beta\left(T-T_{r e f}\right) \\
U \frac{\partial W}{\partial x}+V \frac{\partial W}{\partial y}+W \frac{\partial W}{\partial z}=-\frac{1}{\rho} \frac{\partial P}{\partial z}+v\left(\frac{\partial^{2} W}{\partial x^{2}}+\frac{\partial^{2} W}{\partial y^{2}}+\frac{\partial^{2} W}{\partial z^{2}}\right) \\
U \frac{\partial T}{\partial x}+V \frac{\partial T}{\partial y}+W \frac{\partial T}{\partial z}=\frac{k}{\rho c_{p}}\left(\frac{\partial^{2} T}{\partial x^{2}}+\frac{\partial^{2} T}{\partial y^{2}}+\frac{\partial^{2} T}{\partial z^{2}}\right)
\end{gathered}
$$

The last term in Eq. (4) accounts for local density variations as the buoyancy effect is considered. A source term $S_{m}$ is included in the conservation of mass equation (2) to account for the electrochemical reaction effects on the mass balance corresponding to the consumption of oxygen in the cathode [23]. The total mass can be expressed as

$$
\dot{m}_{\text {in }}+\dot{m}_{m}=\dot{m}_{\text {out }}
$$

where $\dot{m}_{m}$ is the mass flow rate from the porous wall and can be written as

$$
d \dot{m}_{m}=\rho a V_{m} d x
$$

where $d x$ is the incremental length in the main flow direction. The change of mass flow rate due to the mass suction reads

$$
d \dot{m}_{m}=\rho A\left(U_{\text {bulk }}+\frac{\partial U_{\text {bulk }}}{\partial x} d x\right)-\rho A U_{\text {bulk }}=\rho A \frac{\partial U_{\text {bulk }}}{\partial x} d x
$$


where $\partial U_{\text {bulk }} / \partial x$ is the velocity gradient in the main flow direction induced by mass transfer; $U_{\text {bulk }}$ is mean velocity of the main flow, and is calculated as

$$
U_{\text {bulk }}=\frac{\int U d A}{\int d A}
$$

Combining Eqs. (8) and (9), the source term in Eq. (2) reads

$$
S_{m}=\frac{\partial U_{\text {bulk }}}{\partial x}=\operatorname{Re}_{m} \frac{v}{D_{h}} \frac{a}{A}
$$

\section{Boundary Conditions}

Considering the fuel cell function, the thermal boundary conditions and the boundary conditions for the mass transfer were established. For cases with mass transfer, a velocity $V_{m}$ is implemented on the bottom porous wall. As discussed above for fuel cells, heat flux is mainly transferred through this wall (heated bottom wall), while the other walls are impermeable and thermally insulated. The boundary conditions implemented in this study can be written as

$$
\begin{gathered}
U=V-V_{m}=W=0, \quad-k \frac{\partial T}{\partial y}=q_{b} \text { at bottom wall }(y=0) \\
U=V=W=0, \quad q=0 \text { at top and side walls } \\
\frac{\partial U}{\partial z}=\frac{\partial V}{\partial z}=W=\frac{\partial T}{\partial z}=0 \text { at mid-plane }\left(z=\frac{a}{2}\right)
\end{gathered}
$$

\section{Additional Equations}

The Fanning friction factor $f$ is defined as

$$
f=-\frac{1}{2} \frac{D_{h}}{\rho U_{\text {bulk }}^{2}} \frac{d P}{d x}
$$

where $d P / d x$ is the pressure gradient along the main stream direction and $D_{h}$ is the hydraulic diameter defined in the conventional manner,

$$
D_{h}=\frac{4 A}{P^{*}}
$$

where $A$ is the cross-sectional area and $P^{*}$ is the wetted perimeter.

The Nusselt number $\mathrm{Nu}$ can be defined as

$$
\overline{\mathrm{Nu}}_{b}=\frac{\bar{h}_{b} D_{h}}{k}=\frac{q_{b} D_{h}}{k\left(\bar{T}_{b}-T_{\text {bulk }}\right)}
$$


where $\overline{\mathrm{Nu}}_{b}$ is the spanwise average Nusselt numbers at location $x ; q_{b}$ is the wall heat flux, $\bar{T}_{b}$ is the bottom wall spanwise average temperature; $T_{\text {bulk }}$ is the mean streamwise flow temperature in the cross section,

$$
T_{\text {bulk }}=\frac{\int T|U| d A}{\int|U| d A}
$$

The dimensionless axial distance $x^{*}$ in the flow direction for the hydrodynamic entrance region is defined as

$$
x^{*}=\frac{x}{D_{h} \operatorname{Re}}
$$

while as a common practice, the dimensionless coordinate for the thermal entrance region and heat transfer can be defined as

$$
x^{* *}=\frac{x^{*}}{\operatorname{Pr}}
$$

The modified Grashof number reads [18]

$$
\mathrm{Gr}^{*}=\frac{g \beta q_{b} D_{h}^{4}}{k v^{2}}
$$

\section{SOLUTION METHODOLOGY}

The governing differential equations are discretized into algebraic equations by a truncated Taylor series method using a finite-volume method (see, e.g., [24]), and then they are solved by an iterative method.

In this study, Eqs. (2)-(6), together with the boundary conditions (12)-(14), are solved by using an in-house computational fluid dynamics (CFD) code originally developed in [25] and further extended in [26]. In brief, the code is based on a general finite-volume technique with boundary-fitted coordinates for solving the differential equations. The Cartesian coordinate system in the physical space is replaced by a general nonorthogonal coordinate system. The momentum equations are solved for the velocity components on a nonstaggered grid arrangement. The Rhie-Chow interpolation method is used to compute the velocity components at the controlvolume faces. Algorithms based on the TDMA and a modified SIP (used in this study) are employed for solving the algebraic equations. In the code, the convective terms can be treated by the QUICK (used in this study), hybrid, van Leer, and upwind schemes, while the diffusive terms are treated by the central difference scheme. The SIMPLEC algorithm handles the linkage between velocities and pressure.

To include mass transfer effects caused by the electrochemical reaction in fuel cell oxidant ducts, the source term $S_{m}$ in Eq. (2) can be expressed by Eq. (11) as long as the mass suction is small (small $\mathrm{Re}_{m}$ ) and is defined per unit volume. It should be 
noted that this source term is zero in most of the computation domain, and nonzero only in the computation domain neighboring boundaries at the bottom wall. The CFD code used is modified accordingly and the source term $S_{m}$ is implemented in the pressure-correction equation to adjust the mass balance due to mass transfer [23].

The continuity equation (2) is also an additional constraint to deduce the pressure gradient of the momentum equation (3) in the main flow direction $[10,20]$. Based on the fact that the mass transfer is small $\left(\mathrm{Re}_{m} \ll \mathrm{Re}_{i n}\right)$ in fuel cells, the deduced pressure gradient $(d P / d x)_{m}$ by mass transfer can be used to correct the crosssection-averaged axial velocity to take into account mass transfer effects. It reads

$$
\left(\frac{d P}{d x}\right)_{m}=-\rho U_{\text {bulk }}\left(\frac{\partial U_{\text {bulk }}}{\partial x}\right)
$$

where $\partial U_{\text {bulk }} / \partial x$ is the mean velocity gradient induced by mass transfer in Eq. (11). The expression for mean axial velocity $U_{\text {bulk }}$ reads

$$
U_{\text {bulk }}=U_{\text {in }}+\left(\frac{\partial U_{\text {bulk }}}{\partial x}\right) d x
$$

To get a corrected averaged axial velocity, the calculated axial velocity is compared with Eq. (23). If this equation is not satisfied, the pressure gradient in the momentum Eq. (3) is adjusted by Eq. (22), the deduced pressure gradient, until the axial velocity condition is satisfied.

\section{CODE VALIDATION AND TEST CALCULATIONS}

\section{Test of Grid Sensitivity}

Numerical calculations were carried out using various numbers of grid points to check the dependence of the results on the number of grid points. As an example, Tables $1 a$ and $1 b$ present the values of $f \mathrm{Re}$ and $\overline{\mathrm{Nu}}_{b}$, respectively, for various positions $x^{*}$ (or $x^{* *}$ ) at mass suction $\mathrm{Re}_{m}=-2.5$ and $\mathrm{Gr}^{*}=1.75 \times 10^{5}$ for a rectangular duct (aspect ratio 2:1). The table shows that the calculated friction factors and Nusselt numbers do not change significantly when the number of grid points is increased beyond $25 \times 25 \times 250(25 \times 25$ for the cross section, 250 for the main flow direction) for all cases. The uniform control-volume size was employed throughout this study.

Table $1 a$. Influence of grid size on $f$ Re for a rectangular duct $(a / h=2: 1)$

\begin{tabular}{lcccccc}
\hline $\mathrm{Gr}^{*} / \mathrm{Re}_{m}$ & \multicolumn{6}{c}{$1.75 \times 10^{5} /-2.5$} \\
\hline Grid no. & $20 \times 20 \times 325$ & $35 \times 35 \times 200$ & $25 \times 25 \times 250$ & $25 \times 25 \times 300$ & $30 \times 30 \times 250$ & $30 \times 30 \times 300$ \\
\hline$x^{*}=0.002$ & 44.41 & 43.83 & 43.87 & 43.40 & 43.73 & 44.40 \\
$x^{*}=0.005$ & 29.45 & 29.40 & 29.10 & 28.91 & 29.13 & 30.10 \\
$x^{*}=0.03$ & 15.71 & 15.70 & 15.68 & 15.72 & 15.56 & 16.08 \\
$x^{*}=0.074$ & 14.59 & 13.65 & 14.06 & 14.08 & 13.92 & 13.70 \\
\hline
\end{tabular}


Table $1 b$. Influence of grid size on $\overline{\mathrm{Nu}}_{b}$ for a rectangular duct $(a / h=2: 1)$

\begin{tabular}{lcccccc}
\hline $\mathrm{Gr}^{*} / \mathrm{Re}_{m}$ & $1.75 \times 10^{5} /-2.5$ \\
\hline Grid no. & $20 \times 20 \times 325$ & $35 \times 35 \times 200$ & $25 \times 25 \times 250$ & $25 \times 25 \times 300$ & $30 \times 30 \times 250$ & $30 \times 30 \times 300$ \\
\hline$x^{* *}=0.002$ & 11.41 & 12.81 & 11.93 & 11.80 & 12.31 & 12.30 \\
$x^{* *}=0.005$ & 8.46 & 9.44 & 8.89 & 8.86 & 9.19 & 9.16 \\
$x^{* *}=0.03$ & 5.90 & 6.57 & 6.24 & 6.23 & 6.43 & 6.43 \\
$x^{* *}=0.10$ & 5.75 & 6.29 & 6.00 & 6.00 & 6.17 & 6.17 \\
\hline
\end{tabular}

\section{Code Performance and Validation}

As there are no available experimental data for SOFC applications in the literature for verification of the friction factor and $\mathrm{Nu}$ number when combined mass suction and buoyancy force-driven secondary flow are included, calculations have been carried out for pure forced convection and those with mass suction or buoyancy effects. The simulation results of these test calculations are compared with results presented in the literature for the same boundary conditions, see Figures $2 a$ and $2 b$, respectively.

Figure $2 a$ shows the results of fully developed $f \mathrm{Re}$ and $\mathrm{Nu}$ numbers with various mass transfer rates for a square duct $(a / h=1: 1)$ for the same boundary condition as in [10], i.e., one wall with a constant heat flux while the other three walls are thermally insulated. The agreement between our calculations and the results obtained by [10] is satisfactory, with a maximum deviation less than $5 \%$. The present calculations with/without buoyancy effects in the thermal entry region are compared with corresponding experimental results [18] for a rectangular duct $(a / h=10: 1)$ with various Gr* as shown in Figure $2 b$. The same thermal boundary conditions, i.e., the bottom wall has a constant heat flux while the other three walls are insulated, are implemented. For the highest $\mathrm{Gr}^{*}$, it is found that after the first maximum in $\mathrm{Nu}$ is reached, the Nusselt number decreases and begins to show oscillatory behavior in the
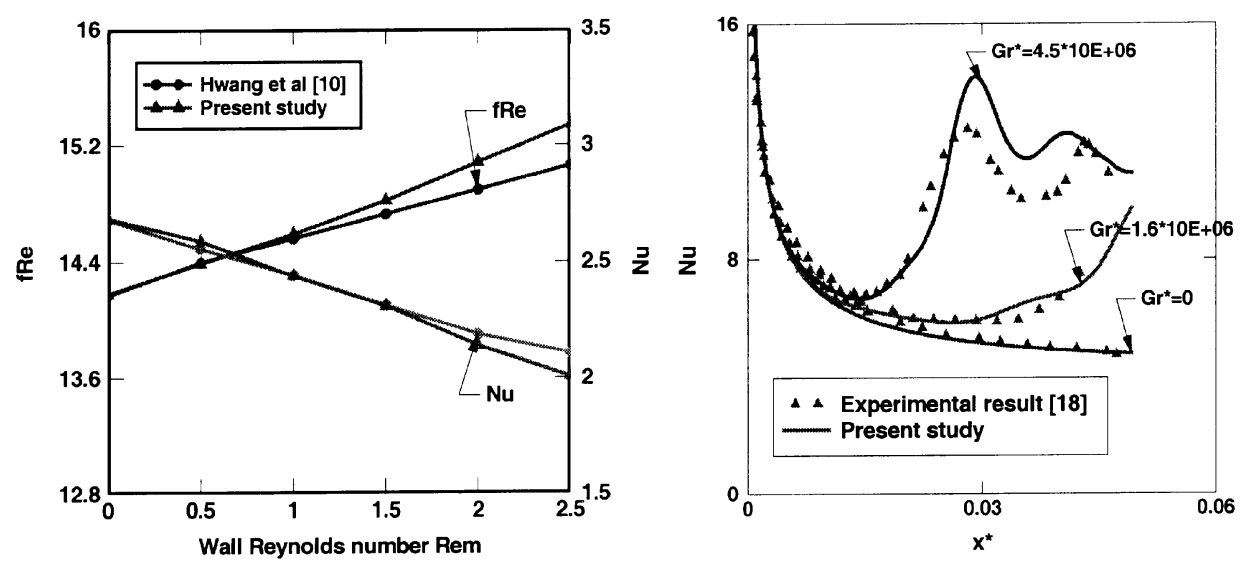

Figure 2. Comparison of $(a) f \mathrm{Re}$ and $\mathrm{Nu}$ numbers with [10] $(a / h=1: 1)$; and $(b) \mathrm{Nu}$ with experimental result of [18] for $\operatorname{Pr}=0.7, \operatorname{Re}=455(a / h=10: 1)$. 
experimental results [18]. Comparison shows that the overall agreement between the present calculations and the experimental results is satisfactory. The maxima and minima are captured, but somewhat mislocated and overpredicted as well. This may be explained by the fact that constant thermal physical properties are assumed in the calculation, but also due to some effect of the grid resolution. For the lower Gr*, which is close to the upper practical limit, the agreement between calculations and experiments is satisfactory.

As a partial verification of the computational results concerning the mass transfer effects on the main flow velocity correction, the corrected Reynolds number Re in this study is compared with that obtained by Hwang et al. [10]. The deviations between the present study and results in [10] are less than $6.0 \%$.

The test calculations performed and discussed above show that the deviations of the calculated results from those presented in the literature are sufficiently small. Thus it is reasonable to believe that the numerical method and code can be used for the present study.

\section{RESULTS AND DISCUSSION}

The study of friction factors and Nusselt numbers in the entrance region is the major objective of the article. The development of buoyancy force-driven secondary flow, mass suction, and its effects on the developing laminar flow in an oxidant fuel cell duct will also be presented and discussed in this section, because it is important and helpful to clarify the gas flow momentum transport and heat transfer mechanism. Calculations have been performed to determine the effects of various parameters on the hydrodynamic and thermal fields, e.g., the important dimensionless parameters such as the modified Grashof number $\mathrm{Gr}^{*}$, mass suction rate $\mathrm{Re}_{m}$, and Reynolds number Re. The flow friction factors and Nusselt numbers for various Gr*, $\mathrm{Re}_{m}$, and $\mathrm{Re}$ are presented. Air with an inlet temperature $T_{\text {in }}=900^{\circ} \mathrm{C}$ is chosen (as in the actual SOFC), while all physical parameters at $1,000^{\circ} \mathrm{C}$ are employed for the calculation except for the density, which varies with air temperature as given in Eq. (4).

\section{Developing Velocity and Temperature Field in a Rectangular Duct}

To have an idea of the combined buoyancy and mass suction effects on a developing mixed-convection flow and heat transfer, it is useful to consider the developing velocity and temperature fields and compare with the limiting case of pure forced convection. Comparison is also extended to include limiting cases of only buoyancy-driven mixed flow or mass suction flow. As mentioned above, there is symmetry in the vertical mid-plane (see Figure $1 b$ ) and results of dimensionless longitudinal velocity, cross-section velocity vectors, and dimensionless isotherms for an aspect ratio $a / h=2: 1$ and $\mathrm{Re}=250$ are presented for the right half of the duct in Figures 3-5.

Cross-section velocity vectors. Figure 3 shows cross-section velocity vectors for pure forced convection $\left(\mathrm{Gr}^{*}=0\right.$ and $\left.\mathrm{Re}_{m}=0\right)$, buoyancy-driven mixed flow $\left(\mathrm{Gr}^{*}=3.5 \times 10^{5}\right.$ and $\left.\operatorname{Re}_{m}=0\right)$, mass suction flow $\left(\mathrm{Gr}^{*}=0\right.$ and $\left.\operatorname{Re}_{m}=-2.5\right)$, and 

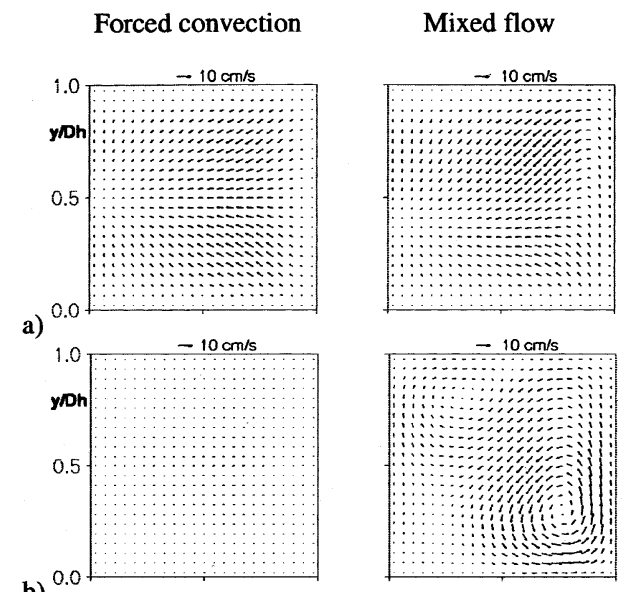

b)
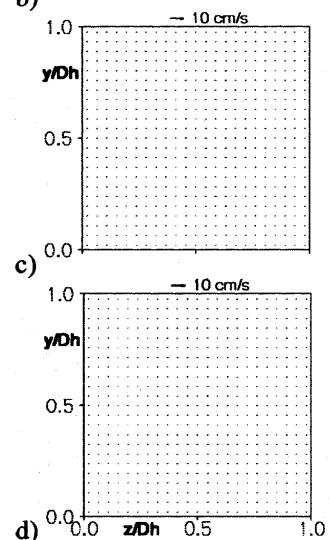
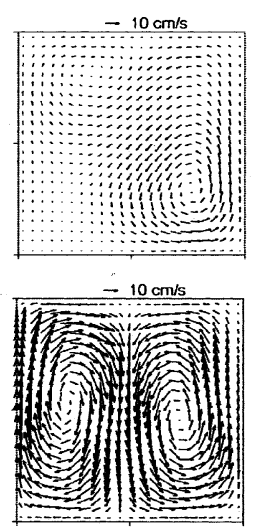

$-10 \mathrm{~cm} / \mathrm{s}$

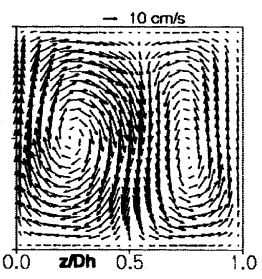

Mass suction

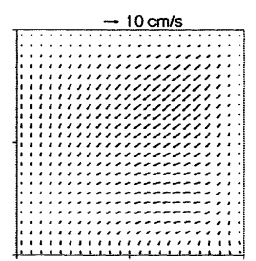

$-10 \mathrm{~cm} / \mathrm{s}$
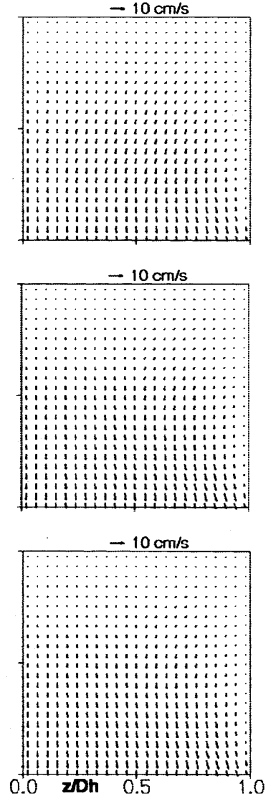

Combined flow

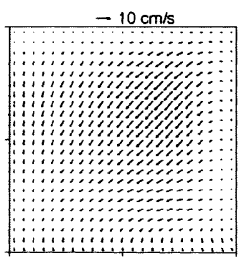

$-10 \mathrm{~cm} / \mathrm{s}$

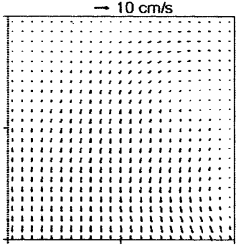

$-10 \mathrm{~cm} / \mathrm{s}$

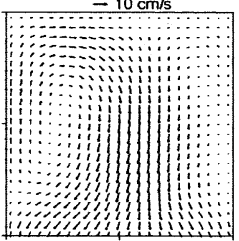

$-10 \mathrm{~cm} / \mathrm{s}$

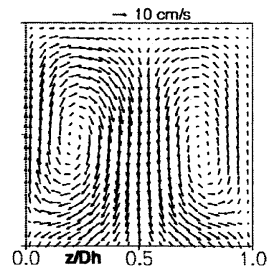

Figure 3. Cross-section velocity vectors for pure forced convection, mixed convection with $\mathrm{Gr}^{*}=3.5 \times 10^{5}$, mass suction $\operatorname{Re}_{m}=-2.5$, and combined flow for aspect ratio $a / h=2: 1, \operatorname{Re}=250$ at: $(a) x^{*}=0.0039$; (b) $x^{*}=0.023 ;(c) x^{*}=0.088 ;(d) x^{*}=0.148$.

combined flow $\left(\mathrm{Gr}^{*}=3.5 \times 10^{5}\right.$ and $\left.\mathrm{Re}_{m}=-2.5\right)$ for selected longitudinal stations $x^{*}$. The scale above the vector plot (i.e., $10 \mathrm{~cm} / \mathrm{s}$ ) is a reference value of the maximum cross-section velocity.

For pure forced convection, it is found that the absolute values of the crosssection velocity vectors decrease with increasing $x^{*}$. For buoyancy-driven secondary flow, a vortex gradually starts to develop at $z / D_{h}=1.0$ at small values of $x^{*}$. As will be clarified in the next sections, the vortex which developed in the lower corner close to the vertical side wall $\left(z / D_{h}=1.0\right)$ is due to a pronounced spanwise temperature gradient caused by the hydrodynamic and thermal-layer development. As will be revealed by the cross-section isotherms, comparatively large temperature gradients and density variations can be found near the mid-plane farther downstream. The large temperature gradient is caused by a relatively weak secondary flow and a reduced thermal energy transfer close to the mid-plane relative to the near side wall. Then the secondary flow develops into a pair of counterrotating vortices. 
Forced convection

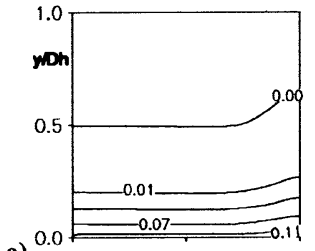

a)

b)

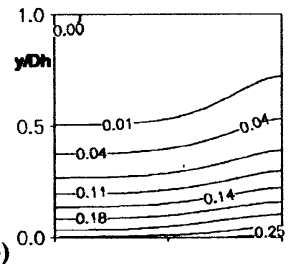

c)
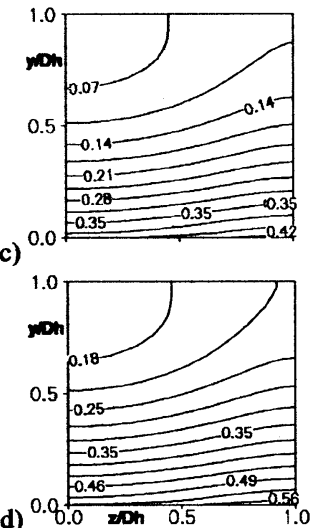

Mixed flow
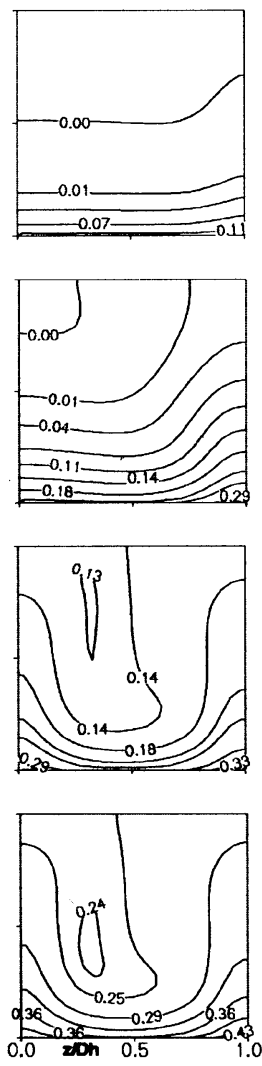

Mass suction
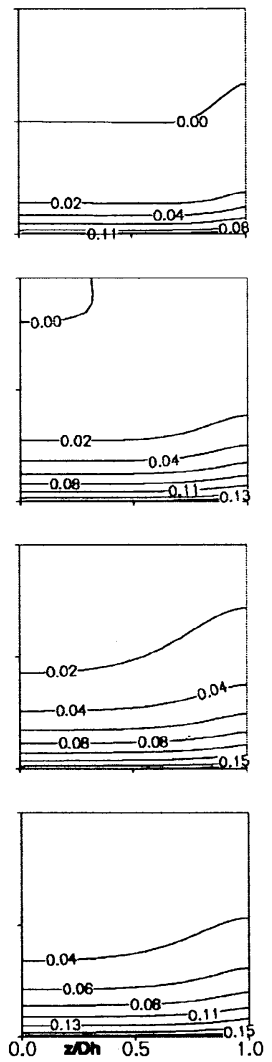

Combined flow
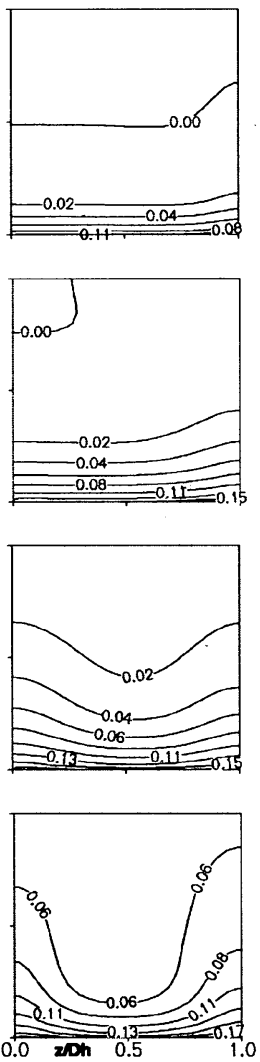

Figure 4. Dimensionless temperature difference $\left(T-T_{\text {in }}\right) /\left(q_{b} D_{h} / k\right)$ for pure forced convection, mixed convection with $\mathrm{Gr}^{*}=3.5 \times 10^{5}$, mass suction $\operatorname{Re}_{m}=-2.5$, and combined flow for aspect ratio $a / h=2: 1$, $\operatorname{Re}=250$ at: $(a) x^{*}=0.0039 ;(b) x^{*}=0.023 ;(c) x^{*}=0.088 ;(d) x^{*}=0.148$.

In the inlet region (Figure $3 a$ ) for mass suction, the cross-section velocity vectors near the bottom wall are downward due to the mass suction effect, while the fluid moves toward the center in the core region by the entrance effect. However, the position of the center moves downward until the center disappears as the flow goes farther downstream (Figures $3 b-3 d$ ). Thus the cross-section velocity vector is downward, and it is also noted that the transverse velocity is relatively large at the bottom wall region, where the mass transfer occurs, but small at the top wall region. For combined flow, similar cross-section velocity development of mass suction can be found in the entrance region (see Figures $3 a$ and $3 b$ ), because the buoyancy-driven secondary flow is weak, and then mass suction flow dominates the cross-section velocity development. Farther downstream (see Figure $3 c$ ), a weak vortex near the $z / D_{h}=1.0$ region together with the second vortex near the mid-plane can be found, until the secondary flow develops also into a pair of counterrotating vortices (see Figure $3 d$ ). It is clear that the downward cross-section velocity caused by mass 

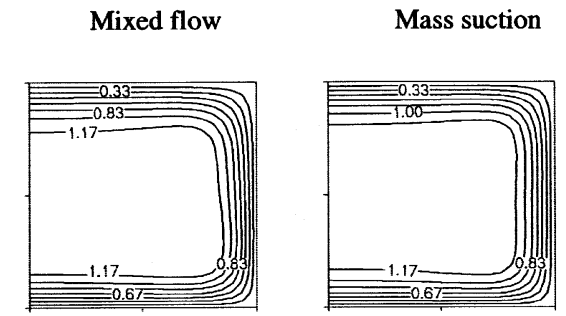

\section{Combined flow}

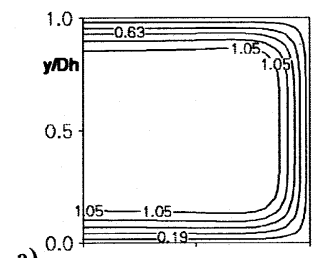

a)
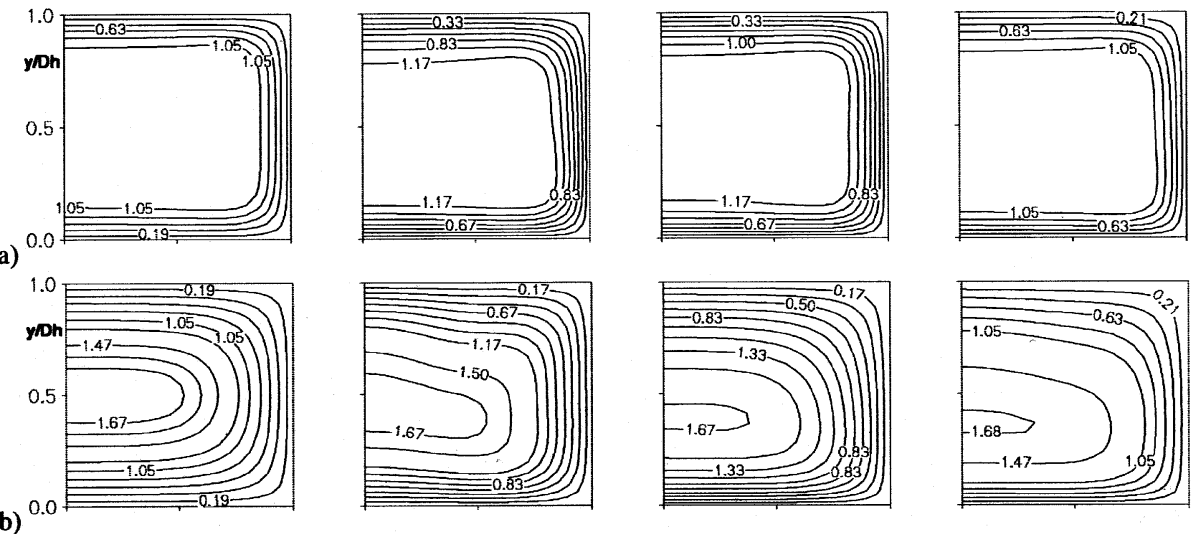

b)
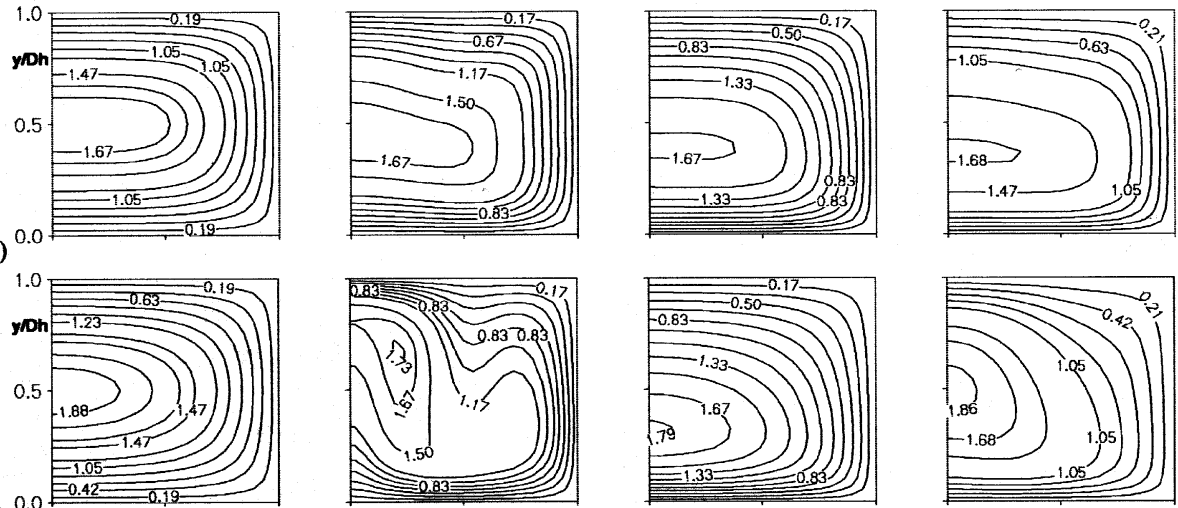

c)
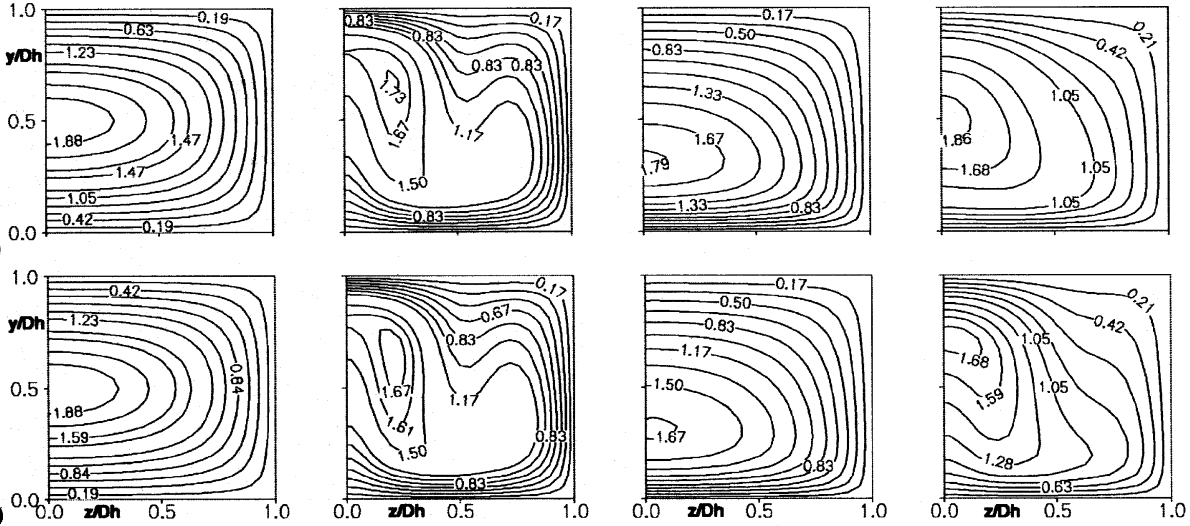

Figure 5. Dimensionless axial velocity contours $\left(U / U_{\text {in }}\right)$ for pure forced convection, mixed convection with $\mathrm{Gr}^{*}=3.5 \times 10^{5}$, mass suction $\mathrm{Re}_{m}=-2.5$, and combined flow for aspect ratio $a / h=2: 1, \mathrm{Re}=250$ at: (a) $x^{*}=0.0039 ;(b) x^{*}=0.023 ;(c) x^{*}=0.088 ;(d) x^{*}=0.148$.

suction decreases the buoyancy-generated upward flow along the side wall and midplane, and enhances the downward flow between two vortices. It is also seen that the strength of the vortices becomes stronger when the axial distance $x^{*}$ increases (Figures $3 c$ and $3 d$ ).

Dimensionless temperature difference $\left(T-T_{\text {in }}\right) /\left(q_{b} D_{h} / k\right)$. The crosssection isotherms are shown in Figure 4 for the same cases and the same longitudinal stations as in Figure 3. For pure forced convection, it is clearly shown that the heat generated at the bottom wall penetrates into the fluid and makes it warmer in the main flow direction (increasing $x^{*}$ ). It is also clear that the cross-section temperature distribution at a certain $y / D_{h}$ is almost uniform, except for the nonuniformity and slightly high temperature which appears in the lower corner close to the vertical side wall $\left(z / D_{h}=1.0\right)$. This temperature increase is due to the slow-moving fluid in the hydrodynamic boundary layer, and it can decrease the contribution of heat transfer 
from the bottom wall. The cross-section isotherms for mixed flow are very similar to those of pure forced convection at upstream positions (Figures $4 a$ and $4 b$ ). A temperature gradient is generated at the entire bottom wall, with a pronounced gradient near the lower corner close to vertical side wall. The buoyancy force generated by this temperature gradient (density gradient) is a source of vortex generation which was observed initially near the lower corner in Figure $3 b$. The vortex close to the vertical side wall advects heated fluid to the top wall and unheated fluid from the core to the heated bottom wall. A temperature gradient appearing near the mid-plane provides the suitable conditions for another secondary flow. A pair of counterrotating vortices is formed (see Figure $3 d$ ), which advects heated fluid from the bottom wall in the areas close to the vertical side wall and mid-plane, and cool fluid to the bottom wall between them.

For mass suction flow, the cross-section isotherm development looks similar to that of pure forced convection. As part of the thermal energy is carried away by the extracted fluid from the bottom wall, the temperature of the fluid arising by bottom wall heat flux increases slowly along the axial distance. The nonuniformity of temperature distribution which appears in the lower corner close to the vertical side wall $\left(z / D_{h}=1.0\right)$ becomes weaker if compared to pure forced convection. For combined flow in the entrance region (see Figures $4 a$ and $4 b$ ), similar isotherms with those of mass suction can be observed due to the fact that buoyancy-driven secondary flow is weaker and mass suction dominates. Farther downstream (Figures $4 c$ and $4 d$ ), the buoyancy-driven secondary vortices carry the heated fluid from the bottom wall region to the top cool wall region by the upward flow developed near the side-wall and mid-plane. The slightly higher temperature distribution can be found near the side-wall region, but also near the mid-plane region. Low temperatures are found between two vortices due to the downward flow carrying cool flow from the top wall region. The temperature of the fluid increases slowly along the axial distance for combined flow. This can also be found if comparison with the case of buoyancydriven secondary flow is carried out.

Dimensionless axial velocity. Figure 5 shows dimensionless axial velocity contours $\left(U / U_{\text {in }}\right)$ for the same cases as in Figures 3 and 4 . For the pure forced convection, it is very clear that the axial velocity contours represent the development of the hydrodynamic boundary layer. There is a fluid acceleration (bigger contour value) in the core, which compensates for the development of the boundary layer. It is also clear that the axial velocity contours are symmetric with respect to the horizontal central plane $\left(y / D_{h}=0.5\right)$. Due to the secondary flow generated by the buoyancy force, the uniform distribution and symmetry of the axial velocity no longer exists, and the position of maximum contour values moves toward the bottom horizontal wall with increasing $x^{*}$ until $x^{*}=0.023$ (Figure 5b). Farther downstream (Figure $5 c$ ), the distribution of axial velocity contours is more complicated and the maximum contour values appear in the position corresponding to the mid-plane vortex in Figure 3, and this is kept to the end of duct (Figure $5 d$ ).

As for mass suction, mass subtraction is induced and thus the axial velocity will be decreased. Dimensionless axial velocity contours for mass suction shows that the maximum velocity is smaller than that of pure forced convection, and it becomes more clear farther along the downstream of the duct. The downward cross-section 
flow (see Figure 3) generated by mass suction shifts the peak of axial velocity toward the porous bottom wall. For combined flow, the thermal buoyancy effects together with mass suction are taken into account, and the axial velocity is distorted by the buoyancy force after a certain axial distance (see Figure $5 c$ ). The buoyancy effect on the combined flow becomes more apparent along the duct farther downstream (Figure 5d).

Effects of Grashof number $\mathrm{Gr}^{*}$ and mass suction rate $\mathrm{Re}_{\boldsymbol{m}}$ on crosssection velocity vectors for combined flow. To understand buoyancy forcedriven secondary flow and mass suction effects on the combined gas flow and heat transfer, cross-section velocity vectors for various Grashof numbers and mass suction rates are compared at the same longitudinal stations as shown in the last sections, and the results are presented in Figure 6.

As mentioned before, both the buoyancy force and mass suction have significant effects on the velocity and temperature development. By comparing Figures $6 a, 6 b$, and $6 c$, which are for various $\mathrm{Gr}^{*}$ at the same mass suction rate $\left(\operatorname{Re}_{m}=-1.0\right)$, all cross-section velocity vectors look similar in the entrance region $\left(x^{*}=0.0039\right)$, except that the position of the center in the core region moves down as $\mathrm{Gr}^{*}$ increases. Buoyancy force-generated secondary flow becomes obvious at $x^{*}=0.023$, and a pair of vortices is noticed for large $\mathrm{Gr}^{*}$ (Figures $6 b$ and $6 c$ ) at $x^{*}=0.088$. However, only one vortex is observed for small $\mathrm{Gr}^{*}$ (Figure $6 a$ ). The same trend, i.e., the strength and number of vortices generated depend mainly on the value of $\mathrm{Gr}^{*}$ for mixed flow, can also be noticed for combined flow. Concerning the mass suction effects, Figures $6 a, 6 b$, and $6 c$ are compared with Figures $6 d, 6 e$, and $6 f$, respectively, for the same $\mathrm{Gr}^{*}$ but different mass suction rates. It is found that an increase in mass suction rate can enhance the cross-section vector at small $\mathrm{Gr}^{*}$ (see Figures $6 a$ and $6 d$ ) or decrease the strength of velocity vectors when $\mathrm{Gr}^{*}$ is large (see Figures $6 c$ and $6 f$ ). For the case of $\mathrm{Gr}^{*}=1.75 \times 10^{5}$, the mid-plane vortex becomes weaker by increasing the mass suction rate, and thus only one vortex in the side-wall region can be clearly found. This is due to the fact that the downward flow caused by the mass suction can balance the upward flow, and enhance downward flow generated by buoyancy force. For large $\mathrm{Gr}^{*}$, upward flow appears at both the side-wall and mid-plane regions, but only at the side-wall region for small $\mathrm{Gr}^{*}$ [21]. This is the reason the increase in mass suction rate and Grashof number cannot always result in enhancement of the crosssection secondary flow.

As discussed above, both mass suction and buoyancy-driven secondary flow have significant effects on the temperature development, strength of velocity vectors, and number of vortices generated. The effects depend mainly on the value of Grashof number and mass suction rate.

\section{Longitudinal Distribution of Average Friction Factor $f$ and Nusselt Number $\overline{\mathbf{N u}}_{b}$ in a Rectangular Duct}

The variations of cross-section-averaged skin friction $f$ Re and Nusselt number $\overline{\mathrm{Nu}}_{b}$ along the axial direction for various characteristic parameters (e.g., $\mathrm{Re}_{m}, \mathrm{Gr}^{*}$, and $\mathrm{Re})$ are shown and discussed in this section. For pure forced convection $\left(\mathrm{Gr}^{*}=0\right.$ and $\operatorname{Re}_{m}=0$ ), both the friction factor $f$ and Nusselt number $\overline{\mathrm{Nu}}_{b}$ rapidly decay due 

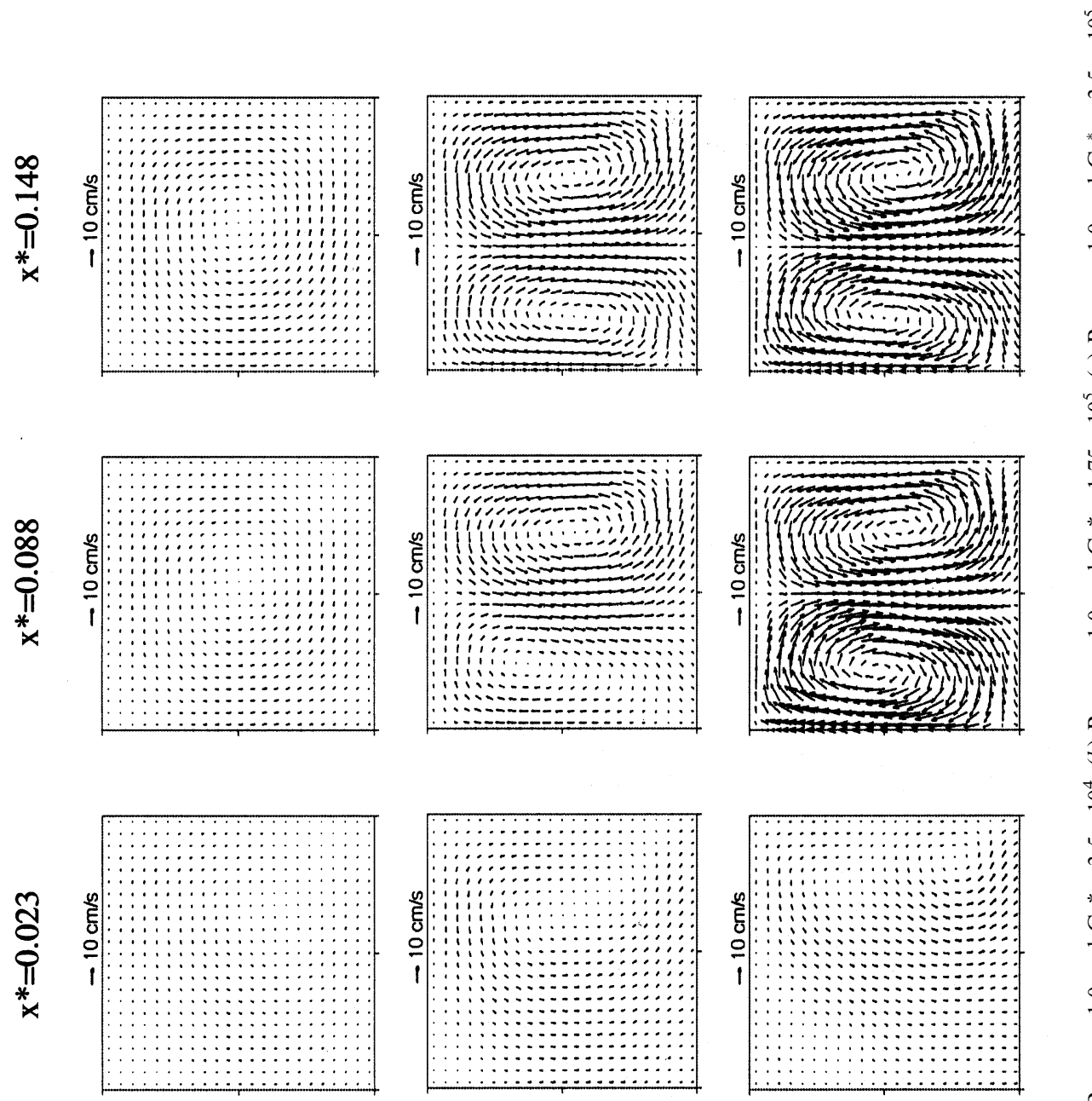

2

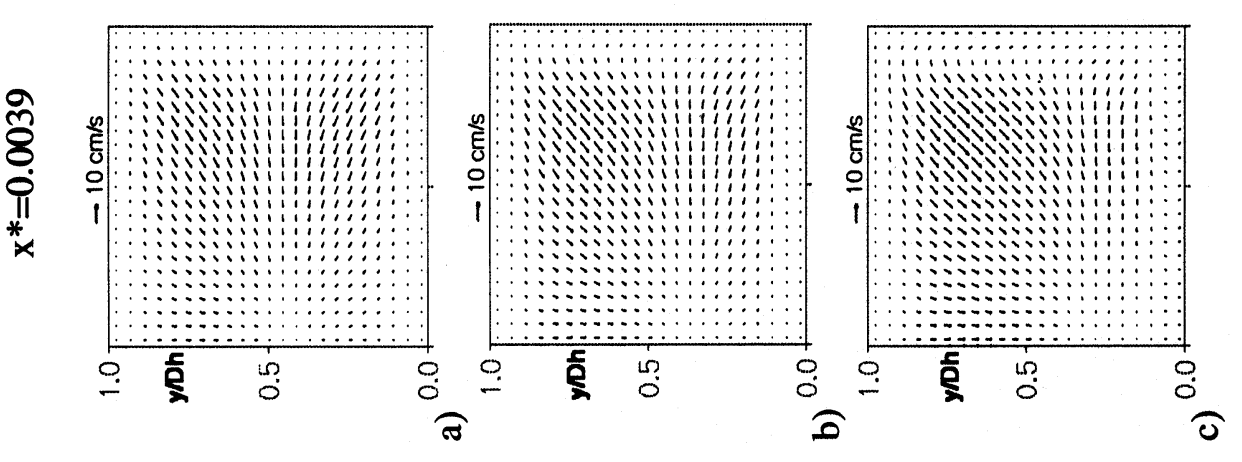



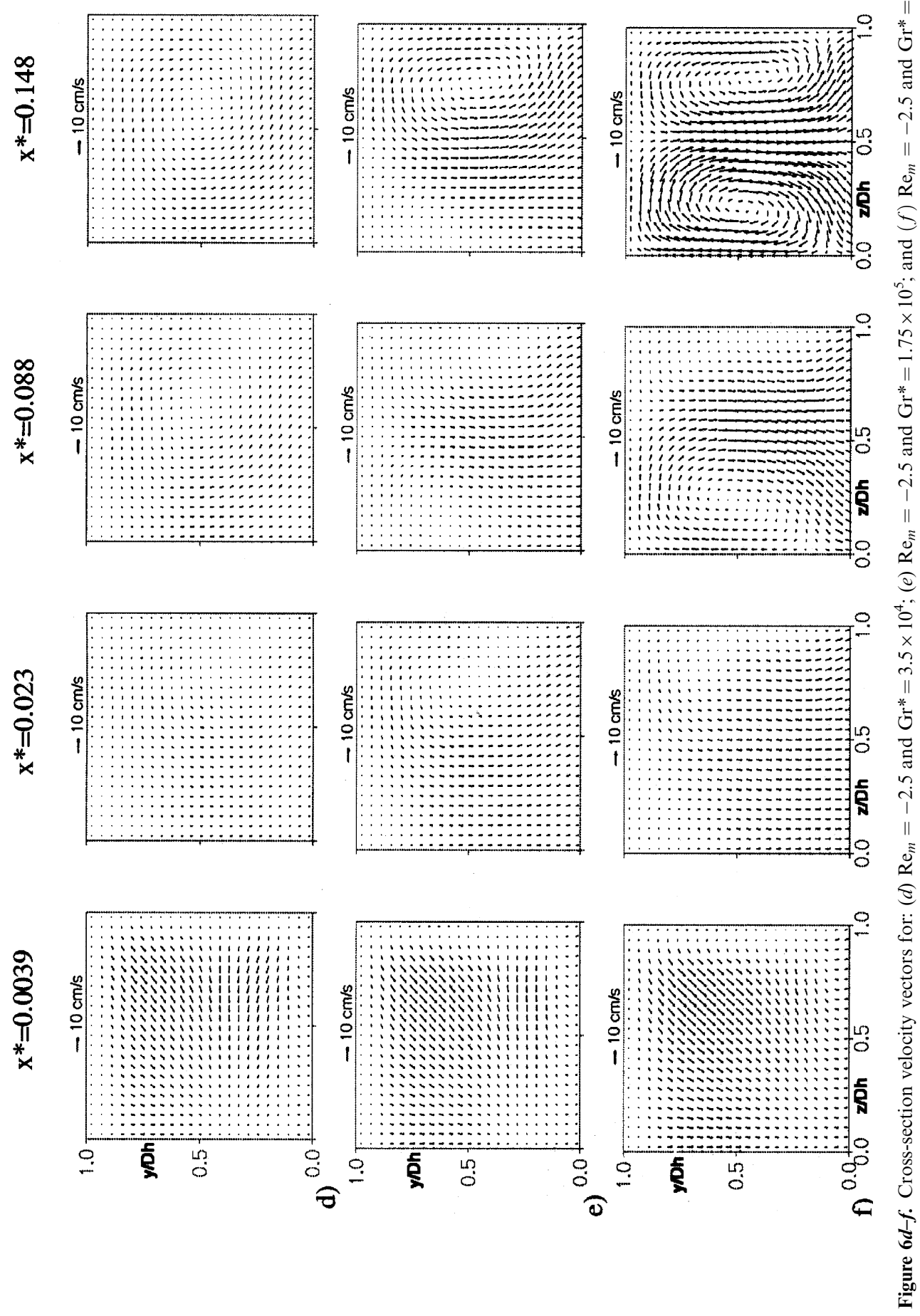


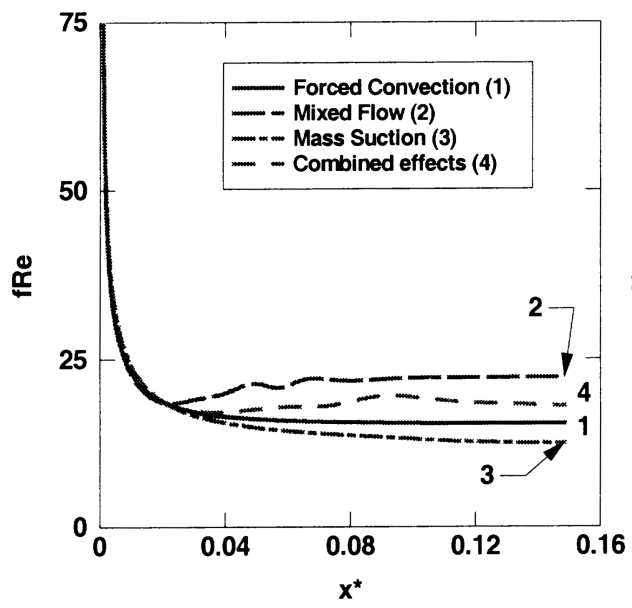

a)

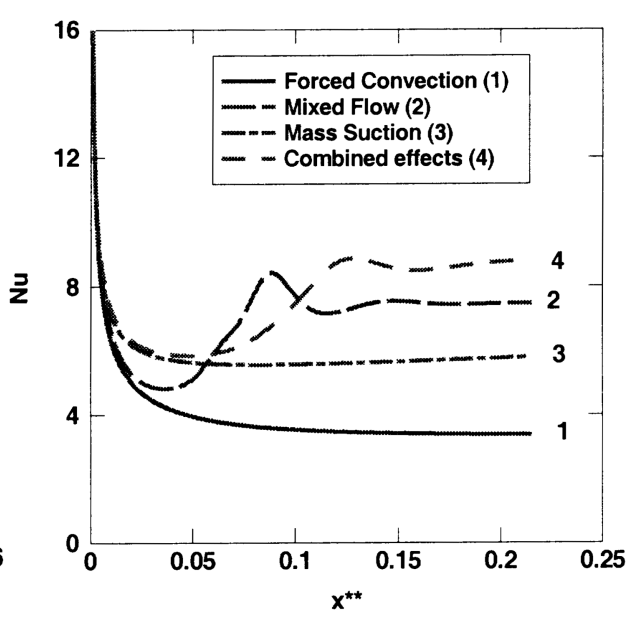

b)

Figure 7. Mass suction, buoyancy, and combined flow effects on: (a) $f \operatorname{Re} ;(b) \overline{\mathrm{Nu}}_{b}$ at $\operatorname{Re}=250$, $\mathrm{Re}_{m}=-1.0, \mathrm{Gr}^{*}=3.5 \times 10^{5}$.

to the hydrodynamic and thermal boundary-layer development and approach their fully developed values (see Figure 7) at certain downstream positions $x^{*}\left(x^{* *}\right)$, respectively. For the mixed-convection flow, similar results of rapid decay of both friction factor and Nusselt number $\overline{\mathrm{Nu}}_{b}$ in the near-entrance region are also shown in Figure 7. The influence on the local friction factor $f$ and Nusselt number $\overline{\mathrm{Nu}}_{b}$ caused by buoyancy effects is negligible up to a certain position $x^{*}$ (or $x^{* *}$ ), depending mainly on the magnitude of Gr* and Reynolds number Re. Farther downstream, the buoyancy effects create a substantial enhancement in both $f \mathrm{Re}$ and $\mathrm{Nu}$ numbers. For a larger value of $\mathrm{Gr}^{*}\left(\mathrm{Gr}^{*}=3.5 \times 10^{5}\right.$ in this case), Figure 7 shows some weak oscillations for both $f$ Re and $\mathrm{Nu}$ numbers caused by the generated secondary flow, i.e., fluid recirculation between the cold core and heated bottom wall (detailed discussions are found in [21] and are not repeated here).

For the case of suction, the mass transfer induces mass flow reduction in the duct, and thus the axial velocity and its gradient at the duct wall region decrease (see Figure 5). As part of the thermal energy is carried away by the extracted mass, the thermal boundary-layer thickness is reduced and the temperature difference between the heated bottom wall and the bulk fluid is reduced by this suction effect. Thus the friction factor $f$ Re is decreased while the Nusselt number $\overline{\mathrm{Nu}}_{b}$ is increased, which can be found in Figure 7. For the case of combined mass suction and buoyancy-driven mixed flow, both $f \operatorname{Re}$ and $\overline{\mathrm{Nu}}_{b}$ follow those curves for only mass suction effect up to a certain distance, due to weaker buoyancy effects in the near-entrance region. As the fluid proceeds downstream, the buoyancy forces increase both $f$ Re and $\overline{\mathrm{Nu}}_{b}$. Figure 7 shows that the friction factor $f$ Re of combined flow is smaller than that of mixed flow, due to the fact that mass suction decreases the $f$ Re. On the other hand, $\overline{\mathrm{Nu}}_{b}$ is bigger than that for mixed flow because the mass suction increases the $\overline{\mathrm{Nu}}_{b}$ too. The small oscillations of $\overline{\mathrm{Nu}}_{b}$ found for combined flow shows that buoyancy- 

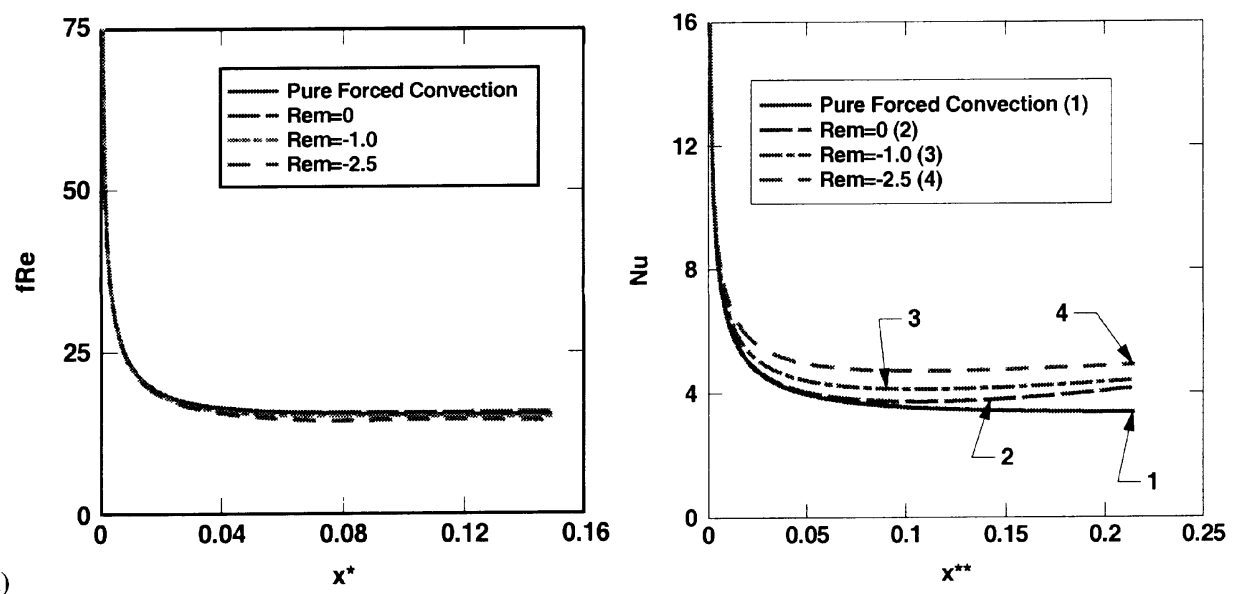

a)
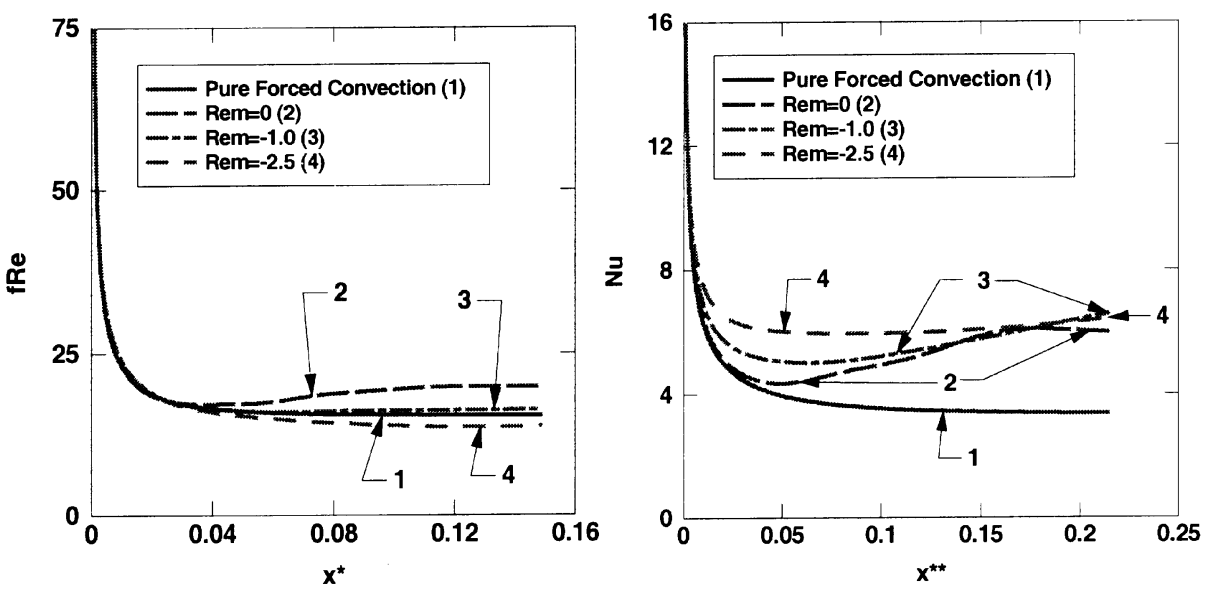

Figure 8. Effects of mass suction rate on $f$ Re (left) and $\overline{\mathrm{Nu}}_{b}$ (right) of combined flow with (a) $\mathrm{Gr}^{*}=3.5 \times 10^{4}$ and $(b) \mathrm{Gr}^{*}=3.5 \times 10^{5}$ at $\mathrm{Re}=250$.

driven secondary flow has stronger effects than mass suction in this case. This is confirmed by Figure $6 c$.

The effects of mass suction rate on the cross-section-averaged $f \operatorname{Re}$ and $\overline{\mathrm{Nu}}_{b}$ are shown in Figure 8 for various Gr*. As shown in Figure $8 a$ for $\mathrm{Gr}^{*}=1.75 \times 10^{4}$, it is clear that increasing the mass suction rate has the effects of decreasing $f \operatorname{Re}$ and increasing $\overline{\mathrm{Nu}}_{b}$. A larger mass suction rate $\left(\mathrm{Re}_{m}=-2.5\right)$ contributes to a larger axial velocity gradient, while a smaller temperature difference between the heated wall and bulk fluid occurs due to increased mass and thermal energy removal from the duct. As seen in Figure 8b, the same trend that an increase of the mass suction rate decreases $f$ Re is also found for a large $\mathrm{Gr}^{*}$. The trend of increasing $\mathrm{Nu}$ by increasing the mass suction rate at small $\mathrm{Gr}^{*}$ is not found for large $\mathrm{Gr}^{*}$. Weak oscillations in $\overline{\mathrm{Nu}}_{b}$ at small mass suction rate $\left(\mathrm{Re}_{m}=-1.0\right.$ and 0 , respectively) are obtained (see Figure $8 b$ ). However, a more flat $\overline{\mathrm{Nu}}_{b}$ distribution along the main flow direction without oscillation can be found for a large mass suction rate $\left(\operatorname{Re}_{m}=-2.5\right)$. This can be 

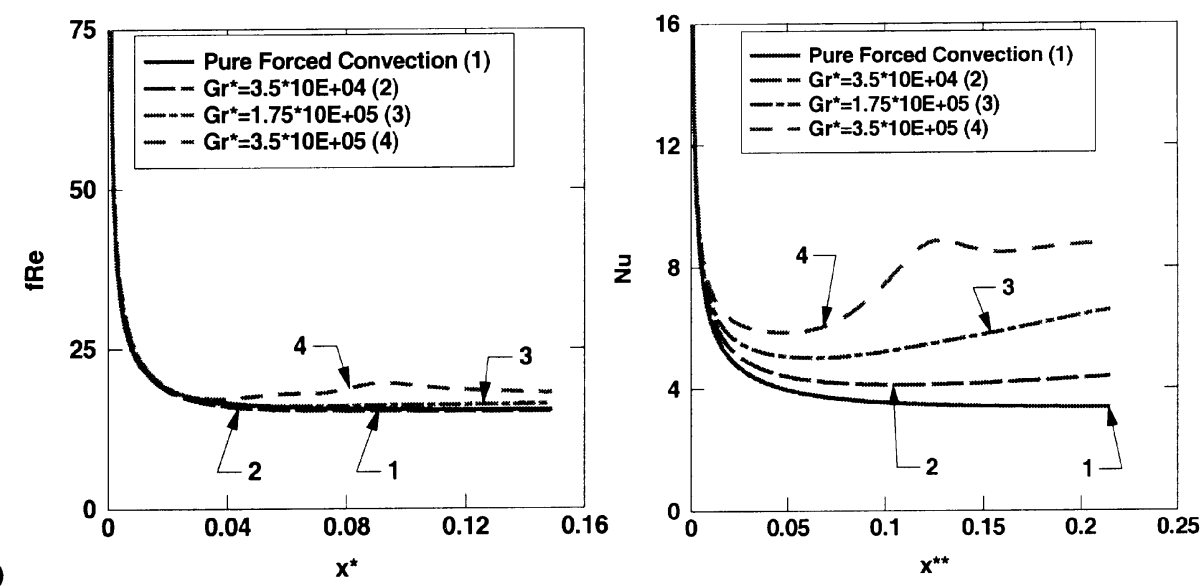

a)
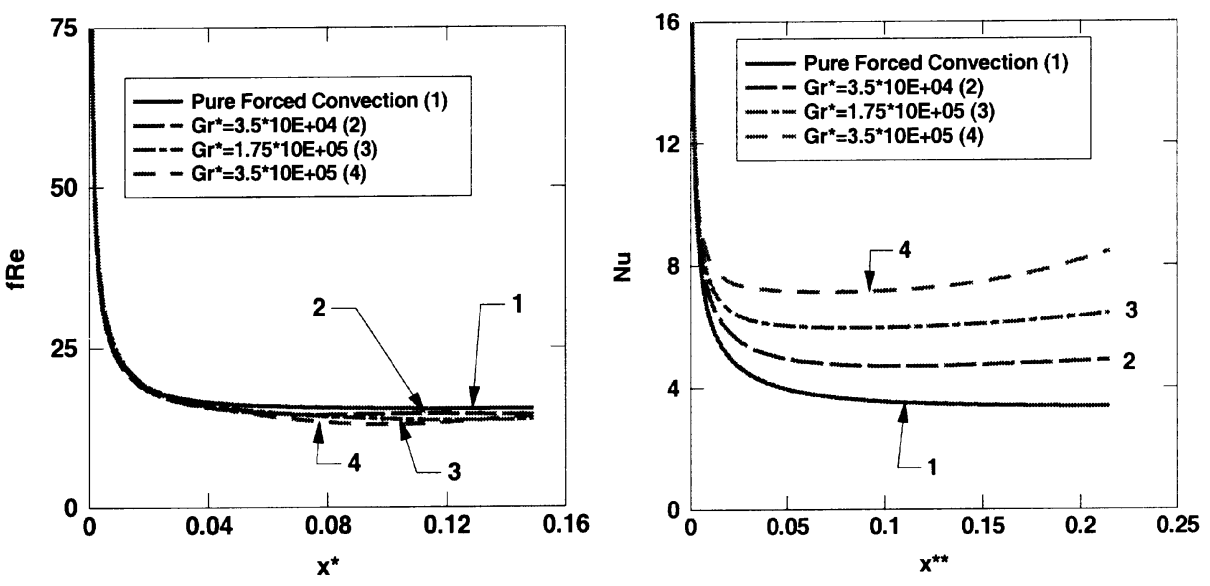

Figure 9. Buoyancy effects on $f \operatorname{Re}$ (left) and $\mathrm{Nu}$ (right) of combined flow at $(a) \operatorname{Re}_{m}=-1.0$ and $(b)$ $\operatorname{Re}_{m}=-2.5$ at $\operatorname{Re}=250$.

understood from Figure 6 because, in contrast to pure forced convection, a large $\mathrm{Re}_{m}$ at large $\mathrm{Gr}^{*}$ makes the strength of secondary flow weaker than that at small $\mathrm{Re}_{m}$, as discussed previously.

Figure 9 shows the cross-section-averaged friction factor $f$ Re and Nusselt number for various $\mathrm{Re}_{m}$ and $\mathrm{Gr}^{*}$ with focus on the buoyancy effects on combined flow at fixed mass suction rates $\mathrm{Re}_{m}=-1.0$ and $\mathrm{Re}_{m}=-2.5$, respectively. In the plots, the buoyancy effects can be negligible up to a certain axial distance for both mass suction rates. This distance depends mainly on $\mathrm{Gr}^{*}$. The larger the $\mathrm{Gr}^{*}$ value is, the shorter the distance is. Comparing Figures $9 a$ and $9 b$ for $f \mathrm{Re}$, it is found that friction factors $f$ Re are close to those of pure forced convection even if there is small deviation along the main flow downstream direction. This is attributed to the opposite effect of mass suction and buoyancy-driven secondary flow on $f \operatorname{Re}$, as mentioned earlier. For Nusselt number, increases in $\overline{\mathrm{Nu}}_{b}$ with increasing $\mathrm{Gr}^{*}$ can be clearly noticed from Figures $9 a$ and $9 b$, due to the fact that both mass suction and buoyancy-driven secondary flow can increase $\overline{\mathrm{Nu}}_{b}$. Moreover, a weak oscillation in 


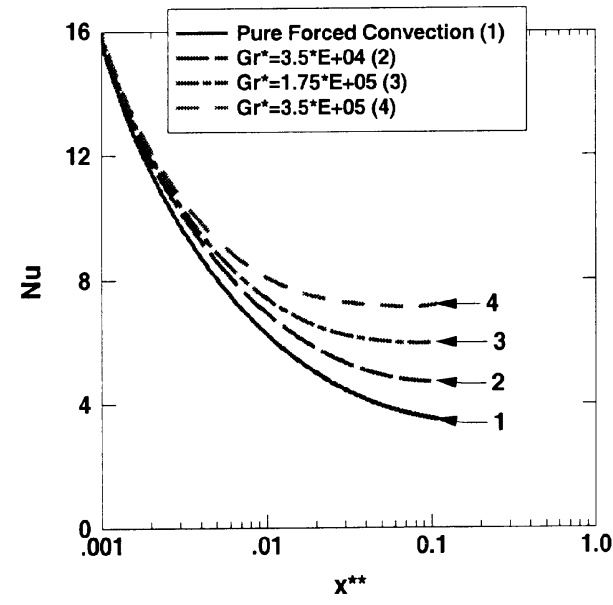

a)

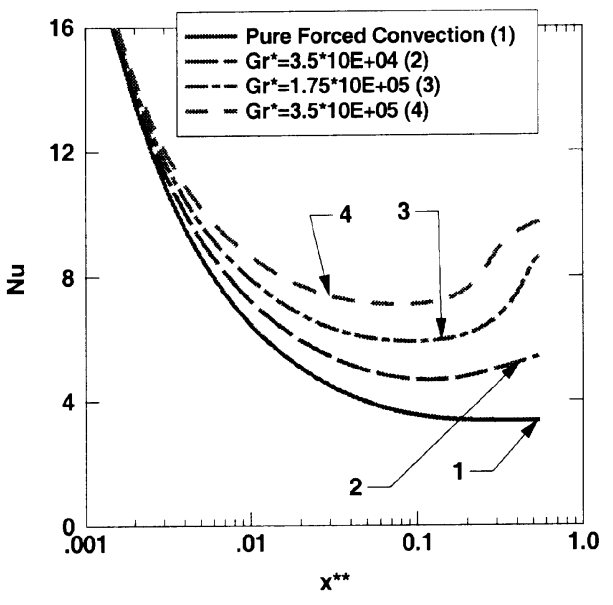

b)

Figure 10. Reynolds number effect on Nusselt numbers with various $\operatorname{Gr} *\left(\operatorname{Re}_{m}=-2.5\right)$ at $(a) \operatorname{Re}=500$, (b) $\operatorname{Re}=100$.

$\overline{\mathrm{Nu}}_{b}$ occurs for large $\mathrm{Gr}^{*}$ and small $\mathrm{Re}_{m}\left(\mathrm{Gr}^{*}=3.5 \times 10^{5}\right.$ and $\mathrm{Re}_{m}=-1.0$, respectively) in Figure $9 a$. This is not the case for a large mass suction rate $\left(\operatorname{Re}_{m}=-2.5\right)$ even at the same Grashof number, because the strength of the secondary flow is decreased when $\mathrm{Re}_{m}$ and $\mathrm{Gr}^{*}$ are large (see Figure 6).

The effects of $\mathrm{Gr}^{*}$ on Nusselt number are shown in Figure 10 at $\mathrm{Re}=500$ and 100, respectively. As discussed, the position where $\overline{\mathrm{Nu}}_{b}$ starts to deviate from pure forced convection and the position of minimum $\overline{\mathrm{Nu}}_{b}$ are shifted upstream with decreasing Re number for buoyancy-driven mixed flow [21]. For combined buoyancy-driven and mass suction flow, the Reynolds number effect on the position of $\overline{\mathrm{Nu}}_{b}$ deviating from that of pure forced convection is clearly seen in Figure 10. This may be due to the fact that the mass suction starts from the entrance and has effects for the whole region of the duct. On the other hand, the buoyancy effect is weak up to a certain distance downstream from the entrance.

As shown and discussed above, there is no evidence that the fully developed condition and the asymptotic values of $f \mathrm{Re}$ and $\overline{\mathrm{Nu}}_{b}$ may be reached in a fuel cell oxidant duct for all operating conditions. By comparing the results of Figures $8 a$ and $8 b$, it is clear that Nusselt number changes slowly for lower $\mathrm{Gr}^{*}$ at fixed $\operatorname{Re}_{m}$. The same trend can be observed for larger $\mathrm{Re}_{m}$ at fixed $\mathrm{Gr}^{*}$. The asymptotic values of $\overline{\mathrm{Nu}}_{b}$ can be observed at high Re (see Figure 10a) but not at low Re (Figure 10b), while the asymptotic value at low $\mathrm{Gr}^{*}$ and small $\mathrm{Re}_{m}$ can be found at $\mathrm{Re}=250$ (see Figures $9 a$ and $9 b$ ). The reason is that the generated secondary flow and downward flow develops slowly at low $\mathrm{Gr}^{*}$ and small $\mathrm{Re}_{m}$. At high $\mathrm{Re}$, the effects are thus small.

\section{Gas Flow and Heat Transfer in a Trapezoidal Duct}

To understand the combined effects of mass suction and buoyancy effects on the gas flow and heat transfer in a trapezoidal duct, simulations have been carried 


\section{Cross-section velocity vectors}

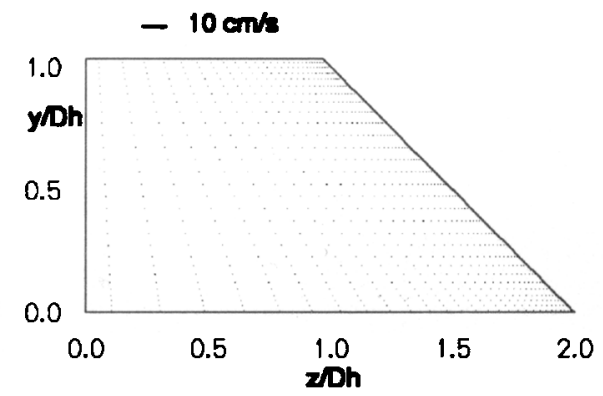

a)

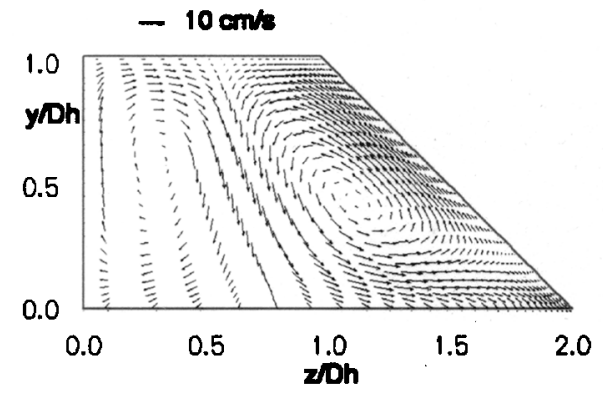

b)

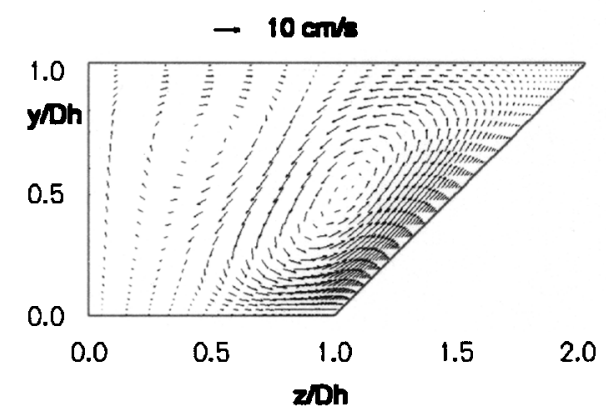

c)

Figure 11. Cross-section velocity vectors and dimensionless temperature difference $\left(T-T_{\text {in }}\right) /\left(q_{b} D_{h} / k\right)$ of a trapezoidal duct (aspect ratio 2:1, base angles $45^{\circ}$ and $135^{\circ}$, respectively) for $(a)$ pure forced convection; (b) and (c) combined flow $\left(\mathrm{Gr}^{*}=1.75 \times 10^{5}, \mathrm{Re}_{m}=-1.0\right)$.

\section{Dimensionless isotherms}
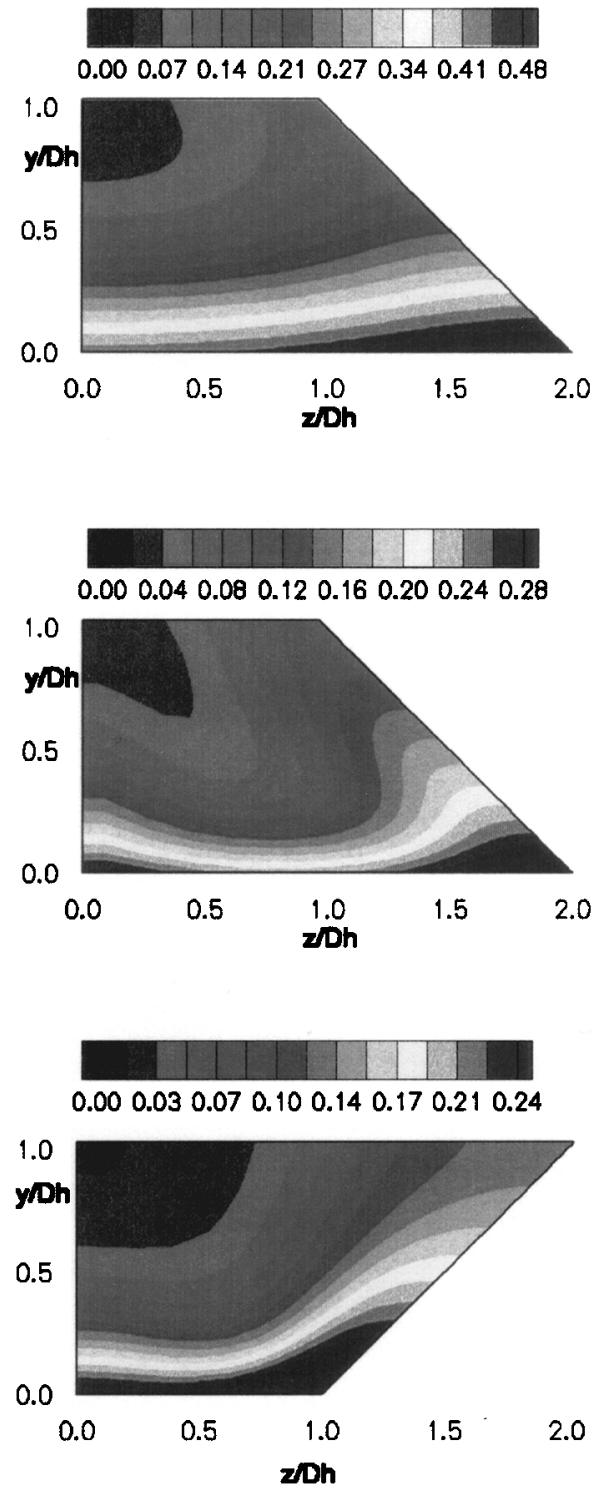

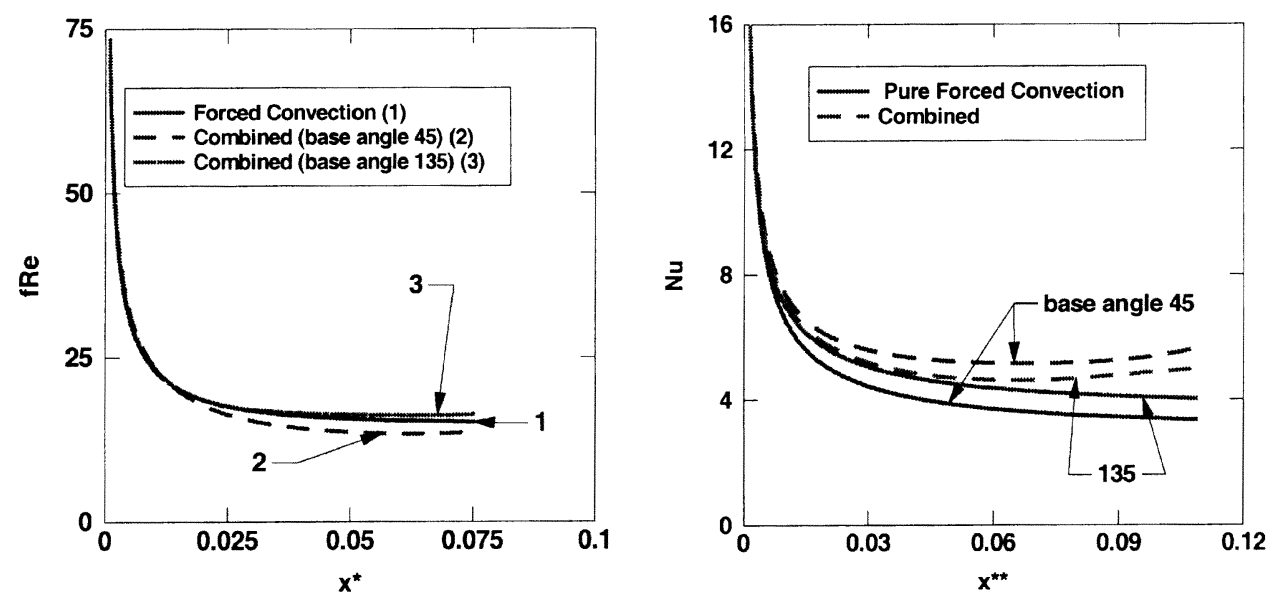

Figure 12. Effects of combined flow on friction factors $f$ Re and Nusselt number $\mathrm{Nu}$ in a trapezoidal fuel cell duct.

out for the limiting cases with an aspect ratio $2: 1$, base angles $45^{\circ}$ and $135^{\circ}$, respectively. Figure 11 shows cross-section velocity vectors and temperature developments for pure forced convection and combined flow, while friction factor $f$ Re and Nusselt number $\mathrm{Nu}$ are shown in Figure 12.

For pure forced convection flow and heat transfer, it is found that the absolute values of the cross-section velocity vectors are very small. By observing Figure 11a, a slightly smaller temperature gradient is clearly found close to the side wall. In contrast to pure forced convection, combined flow generates bigger cross-section velocities. Buoyancy force-generated secondary flow can be clearly observed for both cases of combined flow (Figures $11 b$ and 11c). It is found that the duct with a shorter heating wall and bigger base angle (Figure 11c) generates weaker secondary flows than that with a longer heating wall and smaller base angle (Figure 11b). As mentioned above, part of the thermal energy is carried away by the extracted fluid from the duct. This amount depends on the width of the heating wall. The temperature gradient of the fluid near the bottom wall is thus larger than that of pure forced flow (Figures $11 b$ and 11c).

A decrease in $f \mathrm{Re}$ and an increase in $\mathrm{Nu}$ are found for the case of a small base angle, while both $f$ Re and $\mathrm{Nu}$ are increased for the case of the bigger base angle. It is clear that aspect ratio, base angle, and width of heating wall have significant effects

Table 2. Comparison of $f \mathrm{Re}$ and $\mathrm{Nu}$ for different base angles

\begin{tabular}{lcc}
\hline Base angle & $\begin{array}{c}(f \mathrm{Re})_{\text {combination }} / \\
(f \mathrm{Re})_{\text {pure forced }}\end{array}$ & $\begin{array}{c}(\mathrm{Nu})_{\text {combination }} / \\
(\mathrm{Nu})_{\text {pure forced }}\end{array}$ \\
\hline 45 & 0.92 & 1.66 \\
90 & 1.02 & 1.51 \\
135 & 1.06 & 1.23 \\
\hline
\end{tabular}


on the gas flow and heat transfer in a trapezoidal duct. A comparison of $f \mathrm{Re}$ and $\mathrm{Nu}$ between combined flow and pure forced convection for different angles is shown in Table 2.

It is indicated that the trapezoidal duct with base angle $45^{\circ}$ showing decrease in $f \mathrm{Re}$ and more gain in the $\mathrm{Nu}$ is the preferred cross section if both the gas flow and heat transfer are considered, see Table 2. It should be mentioned that it is desirable to find optimal aspect ratio and base angle for which the heat transfer is large and the friction factor is small, but this is certainly outside the scope of this article. Such a study will be possible when additional information (e.g., allowable pressure drop) is available.

\section{CONCLUSIONS}

Numerical simulations of developing laminar flow and heat transfer in a fuel cell oxidant duct have been presented for combined effects of mass suction and buoyancy force with various Grashof number $\mathrm{Gr}^{*}$, mass suction rate $\mathrm{Re}_{m}$, and Reynolds number Re. The present numerical method was applied to a horizontal rectangular and trapezoidal duct with constant heat flux and mass suction at the bottom wall, and thermal insulation on the other three impermeable walls. These boundary conditions are appropriate for fuel cell oxidant ducts.

From the structure of gas flow and temperature fields, the trend that the initial vortex associated with buoyancy force and appearing in the lower corner close to the vertical side wall is noticed. Mass suction occurring at the bottom wall has effects starting from the entrance. With increasing longitudinal distance $x^{*}$, the resulting secondary flow by combined buoyancy and mass suction propagates toward the entire duct and causes disruption of both the hydrodynamic and thermal boundary layers. Both mass suction rate and Grashof number have significant effects on the secondary flow strength and number of vortices, velocity, and temperature development.

It was also found that both the friction factor $f$ and the Nusselt number $\mathrm{Nu}$ of combined flow decay rapidly in the near-entrance region. Onset of gas flow and heat transfer deviations from pure forced convection is caused by combined effects of the formation of vortices associated with buoyancy and downward flow with mass suction. It was verified that the number and strength of vortices and effects on friction factor and Nusselt number depend mainly on the magnitude of $\mathrm{Gr}^{*}$ and $\operatorname{Re}_{m}$. The mass suction can advance the onset of instability for the combined flow relative to pure forced-convection flow at all Reynolds numbers in this study. The effect of combined flow on the friction factor is less significant than on the heat transfer.

In SOFCs, $\mathrm{Gr}^{*}$ is of the order of $10^{4}-10^{5}$, depending mainly on the duct configuration, and operation parameters such as the generated heat flux and the fluid properties. The buoyancy force-generated secondary flow and the combined effects on the gas flow and heat transfer should be considerated accordingly when the $\mathrm{Gr}^{*}$ is not small (less than $10^{4}$ ). This study may be used for SOFC modeling, as a design tool/adjustment of the flow duct configuration to establish prescribed flow condition and heat transfer, or establish the flow distribution and heat transfer for a given configuration. 


\section{REFERENCES}

1. C. G. Vayenas, P. G. Debenedettl, I. Yentekakls, and L. L. Hegedus, Cross-Flow, SolidState Electrochemical Reactors: A Steady-State Analysis, Ind. Eng. Chem. Fundam., vol. 24, pp. 316-324, 1985.

2. S. Ahmed, C. McPheeters, and R. Kumar, Thermal-Hydraulic Model of a Monolithic Solid Oxide Fuel Cell, J. Electrochem. Soc., vol. 138, pp. 2712-2718, 1991.

3. J. R. Ferguson, J. M. Fiard, and R. Herbin, Three-Dimensional Numerical Simulation for Various Geometries of Solid Oxide Fuel Cells, J. Power Sources, vol. 58, pp. 109-122, 1996.

4. O. Melhus and S. K. Ratkje, A Simultaneous Solution of All Transport Processes in a Solid Oxide Fuel Cell, Denki Kagaku, vol. 64, pp. 662-673, 1996.

5. P. Costamagna, E. Arato, E. Achenbach, and U. Reus, Fluid Dynamic Study of Fuel Cell Devices: Simulation and Experimental Validation, J. Power Sources, vol. 52, pp. 243-249, 1994.

6. R. J. Boersma and N. M. Sammes, Distribution of Gas Flow in Internally Manifolded Solid Oxide Fuel-Cell Stacks, J. Power Sources, vol. 66, pp. 41-45, 1997.

7. J. Yuan, M. Rokni, and B. Sundén, Simulation of Fully Developed Laminar Heat and Mass Transfer in Fuel Cell Ducts with Different Cross Sections, Int. J. Heat Mass Transfer, vol. 44, pp. 4047-4058, 2001.

8. M. Rokni and B. Sundén, A Numerical Investigation of Turbulent Forced Convection in Ducts with Rectangular and Trapezoidal Cross-Section Area by Using Different Turbulence Models, Numer. Heat Transfer, Part A, vol. 30, pp. 321-346, 1996.

9. M. Rokni, A New Low-Reynolds Version of an Explicit Algebraic Stress Model for Turbulent Convective Heat Transfer in Ducts, Numer. Heat Transfer, Part B, vol. 37, pp. 331-363, 2000.

10. G. J. Hwang, Y. C. Cheng, and M.L. Ng, Developing Laminar Flow and Heat Transfer in a Square Duct with One-Walled Injection and Suction, Int. J. Heat Mass Transfer, vol. 36, pp. 2429-2440, 1993.

11. R. B. Kinney, Fully Developed Frictional and Heat-Transfer Characteristics of Laminar Flow in Porous Tubes, Int. J. Heat Mass Transfer, vol. 11, pp. 1393-1401, 1968.

12. J. P. Quaile and E. K. Levy, Laminar Fow in a Porous Tube with Suction, ASME J. Heat Transfer, vol. 97, pp. 66-71, 1975.

13. F. P. Incropera and J. A. Schutt, Numerical Simulation of Laminar Mixed Convection in the Entrance Region of Horizontal Rectangular Ducts, Numer. Heat Transfer, vol. 8, pp. 707-729, 1985.

14. H. V. Mahaney, F. P. Incropera, and S. Ramadhyani, Development of Laminar Mixed Convection Flow in a Horizontal Rectangular Duct with Uniform Bottom Heating, Numer. Heat Transfer, vol. 12, pp. 137-155, 1987.

15. D. G. Osborne and F. P. Incropera, Laminar, Mixed Convection Heat Transfer for Flow Between Horizontal Parallel Plates with Asymmetric Heating, Int. J. Heat Mass Transfer, vol. 28, pp. 207-217, 1985.

16. F. P. Incropera, A. L. Knox, and J. R. Maughan, Mixed Convection Flow and Heat Transfer in the Entry Region of a Horizontal Rectangular Duct, ASME J. Heat Transfer, vol. 109, pp. 434-439, 1987.

17. K. C. Chiu, J. Ouazzani, and F. Rosenberger, Mixed Convection Between Horizontal Plates-I. Entrance Effects, Int. J. Heat Mass Transfer, vol. 30, pp. 1645-1654, 1987.

18. J. R. Maughan and F. P. Incropera, Regions of Heat Transfer Enhancement for Laminar Mixed Convection in a Parallel Plate Duct, Int. J. Heat Mass Transfer, vol. 33, pp. 555-570, 1990. 
19. C. Gau, C. W. Liu, T. M. Huang, and W. Aung, Secondary Flow and Enhancement of Heat Transfer in Horizontal Parallel-Plate and Convergent Ducts Heating from Below, Int. J. Heat Mass Transfer, vol. 42, pp. 2629-2647, 1999.

20. K. Lee and W. Yan, Mixed Convection Heat Transfer in Horizontal Rectangular Ducts with Wall Transpiration Effects, Int. J. Heat Mass Transfer, vol. 41, pp. 411-423, 1998.

21. J. Yuan, M. Rokni, and B. Sundén, Buoyancy Effects on Developing Laminar Gas Flow and Heat Transfer in a Rectangular Fuel Cell Duct, Numer. Heat Transfer, Part A, vol. 39, pp. 801-822, 2001.

22. J. Yuan, M. Rokni, and B. Sundén, Effects of Heated Wall on Mixed Convective Flow and Heat Transfer in a Fuel Cell Duct, in H. Yokokawa, S. C. Singhal (eds.), Solid Oxide Fuel Cells VII (SOFC VII), pp. 922-931, The Electrochemical Society, Pennington, USA, 2001.

23. S. Shimpalee and S. Dutta, Numerical Prediction of Temperature Distribution in PEM Fuel Cells, Numer. Heat Transfer A, vol. 38, pp. 111-128, 2000.

24. H. K. Versteeg and W. Malalasekera, An Introduction to Computational Fluid Dynamics, the Finite Volume Method, Longman, London, 1995.

25. L. Davidson and B. Farhanieh, CALC_BFC, Publication $\mathrm{Nr} 92 / 4$, Department of Thermo- and Fluid Dynamics, Chalmers University of Technology, Göteborg (Gothenburg), Sweden, 1991.

26. M. Rokni, Numerical Investigation of Turbulent Fluid Flow and Heat Transfer in Complex Ducts, Doctoral thesis, Division of Heat Transfer, Lund Institute of Technology, Lund, Sweden, 1998. 